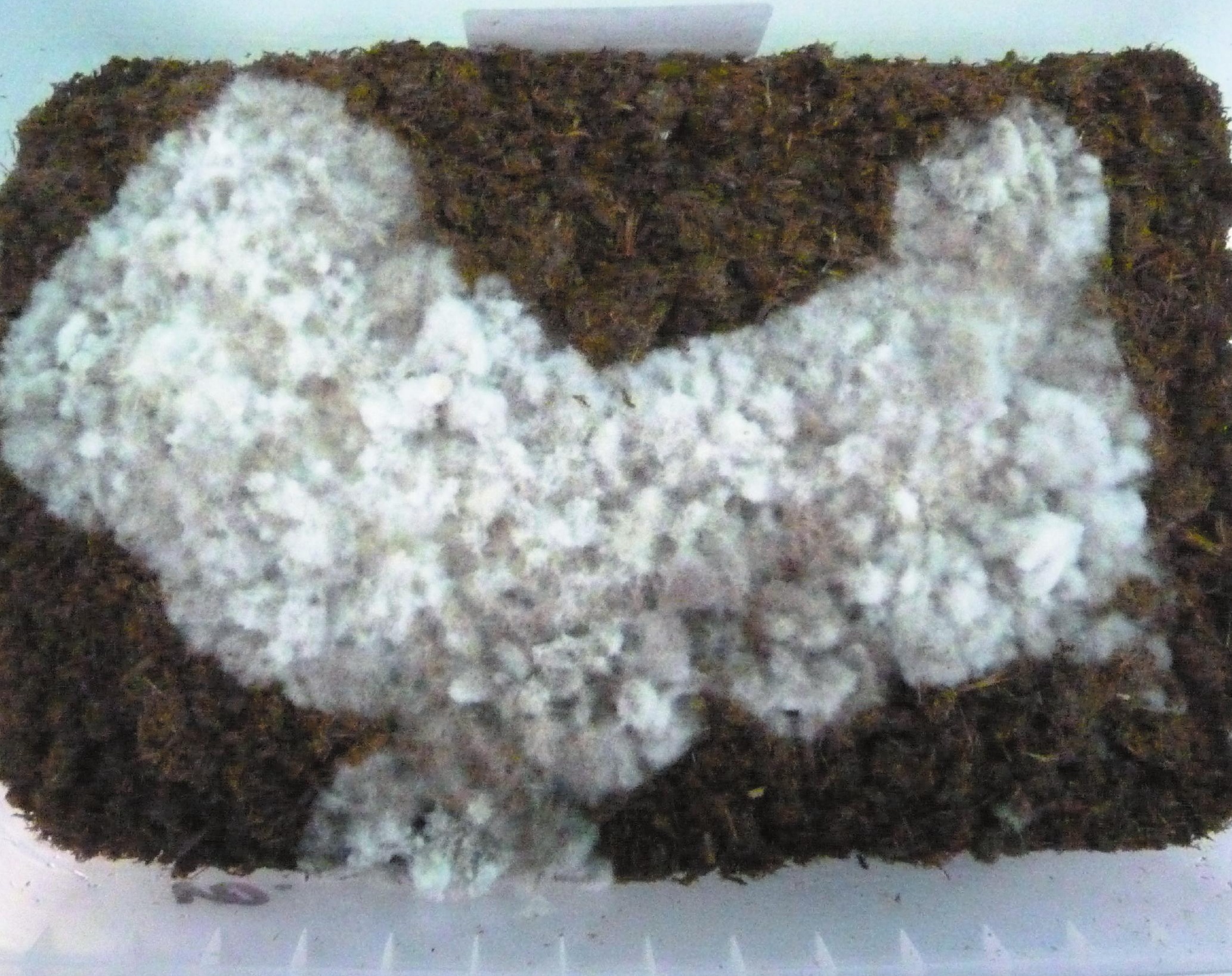

Growth of fungi on alternative substrates and fungal pre-treatment for biogas production

Hellen Elissen, Johan Baars, Stefan Hol, Sabine Schnabel \& Rommie van der Weide Wageningen University \& Research 


\section{Growth of fungi on alternative substrates and fungal pre-treatment for biogas production}

Hellen Elissen, Johan Baars, Stefan Hol, Sabine Schnabel \& Rommie van der Weide

Wageningen University \& Research

This study was carried out by the Wageningen Research Foundation (WR), Business Unit Field Crops and was commissioned and financed by the PPP Biobased valorisation of manure and digestate AF-17052b. This project is financially supported by the Dutch Topsector Agri \& Food. Within the Topsector, private industry, knowledge institutes and the government are working together on innovations for safe and healthy food for 9 billion people in a resilient world.

WR is part of Wageningen University \& Research, the collaboration of Wageningen University and Wageningen

Lelystad, January 2021

Report WPR-832 
Elissen, H., J. Baars, S. Hol, S. Schnabel \& R. van der Weide, 2021. Growth of fungi on alternative substrates and fungal pre-treatment for biogas production. Wageningen Research, Report WPR-832. 32 pp.; 13 fig.; 8 tab.; 19 ref.

This report can be downloaded for free at https://doi.org/10.18174/541326

Summary: This report starts with a literature review on the topic. From literature it is known that fungi can selectively digest lignin, thereby releasing other components which may subsequently be easily converted into biogas during anaerobic digestion of normally recalcitrant compounds. In addition, several authors have found that commercial fungi can be grown on alternative substrates such as digestates. Four substrates (flax shives, solid fractions of ACRRES digestate, Greendal digestate and cow manure) were incubated with 10 fungi species (Coprinus comatus, Ceriporiopsis subvermispora, Pleurotus ostreatus, Pleurotus eryngii, Lentinula edodes, Hypholoma frowardii, Clitocyba dusenii, Bjerkandera adusta, Hypholoma fasciculare, Gymnopilus sapineus and Kuehneromyces mutabilis). Most combinations of substrates and fungi resulted in growth/colonization, except for all combinations with Greendal digestate, probably due to fungicidal compounds. The most successful combinations were those with P. eryngii, P. ostreatus and G. lucidum on ACRRES digestate, flax shives and cow manure, based on visual signs of fungal colonisation (air mycelium). In general, (average) biogas productions from the different substrates with or without fungal pre-treatment did not vary to a large extent and were relatively low (35-73 $\mathrm{nm}^{3}$ biogas per ton product). Although in some graphs a slight positive effect on biogas treatment seemed to be taking place, statistical analysis showed that treatment of cow manure with $P$. ostreatus, $P$. eryngii and G. Iucidum did not significantly increase the amount of biogas that could be collected. Fungal pretreatment of flax shives also did not lead to increased biogas production with $P$. eryngii and G. Iucidum and even to a significantly lower biogas production with $P$. ostreatus.

Keywords: biogas, fungal pre-treatment, fungi, digestate, cow manure, recalcitrant biomass, flax shives, alternative substrates

(C) 2021 Wageningen, Stichting Wageningen Research, Wageningen Plant Research, Business Unit Field Crops, P. O. Box 430, 8200 AK Lelystad, The Netherlands; T +31 320291 111; www.wur.eu/plantresearch

Chamber of Commerce no. 09098104 at Arnhem

VAT NL no. 8065.11.618.B01

Stichting Wageningen Research. All rights reserved. No part of this publication may be reproduced, stored in an automated database, or transmitted, in any form or by any means, whether electronically, mechanically, through photocopying, recording or otherwise, without the prior written consent of the Stichting Wageningen Research.

Stichting Wageningen Research is not liable for any adverse consequences resulting from the use of data from this publication.

Report WPR-832 


\section{Contents}

$\begin{array}{ll}\text { Preface } & 5\end{array}$

$\begin{array}{ll}\text { Summary } & 7\end{array}$

1

$\begin{array}{ll}\text { Introduction } & 9\end{array}$

1.1 Mushroom production on digestates (biogas slurry) and shives 9

$\begin{array}{lll}1.2 & \text { Biogas production from different substrates } & 10\end{array}$

$\begin{array}{lll}1.3 & \text { Pre-treatment of anaerobic digester substrates } & 10\end{array}$

2

$\begin{array}{ll}\text { Materials and methods } & 15\end{array}$

2.1 Growth of fungi on cow manure, digestates and shives $\quad 15$

2.2 Input materials/fungi 16

$\begin{array}{lll}2.3 & \text { Anaerobic digestion tests } & 17\end{array}$

$\begin{array}{lll}2.4 & \text { Statistical analyses } & 17\end{array}$

3

$\begin{array}{lr}\text { Results } & 19\end{array}$

3.1 Growth of fungi on different substrates $\quad 19$

3.2 Biogas production and quality $\quad 22$

$\begin{array}{lll}3.3 & \text { Organic matter breakdown } & 25\end{array}$

$\begin{array}{llr}4 & \text { Discussion and conclusion } & 27\end{array}$

$\begin{array}{llr}5 & \text { Recommendations } & 29\end{array}$

$\begin{array}{ll}\text { References } & 31\end{array}$

Annex 1 Growth results of 10 different fungal species on four substrates $\begin{array}{ll}\text { after } 4 \text { weeks } & 33\end{array}$

Annex 2 pH values and substrate dosages at start and end of anaerobic digestion tests $(n=3)$ 



\section{Preface}

In the Netherlands, there are surpluses of manure and digestates/biogas slurries (digested manure and residual flows), which represent a negative value. At the same time, these residual flows contain valuable ingredients for the production of biomass (as raw material for food and feed products), for improving soil quality and for energy production. The number of feasible business cases in which the residual flow is upgraded has so far been limited. This is due both to the efficiency of the technologies used and the legislation and regulations related to the residual flows.

Recent information from research, scientific literature and companies provides new starting points for a biobased valorisation of manure/digestate streams and improving the efficiency of anaerobic digestion. The innovative aspect of our research is the cultivation of new types of biomass on the residual flows and the use of the conversion products to improve anaerobic digestion. This involves the use of separated manure and digestate products for the cultivation of mushrooms/fungi, worms, insects, specific bacteria and aquatic biomass. The resulting biomass can be further refined and marketed as food, feed and bio-based feedstock. There are also processed manure and digestate products that are valuable as fertilizer products for soil and plant growth, as substrate for improvement of anaerobic digestion or for export/use besides in agriculture. This gives a new interpretation to obligatory manure processing.

The aim of this project is to further explore and substantiate/test these ideas on lab and practical scale, leading to a proof of principles for new bio-based upgrading methods for manure and digestate that can be used in conjunction to better close cycles and/or sell outside regular agriculture.

Bottlenecks in legislation and regulations are explored and put on the agenda. Key figures are also calculated that are necessary for assessing sustainability (e.g. costs, environmental effects) and for supporting legislation (e.g. minerals, food safety).

The livestock sector gains insight into the possibilities of biobased valorisation and better marketing of their most important residual flows. For the SMEs involved, this research provides proof of principle for their technology and input in their business cases. The combined effects of the technologies provide new knowledge, methods and research directions for science. In a social context, the use and upgrading of manure and digestates in other ways also contributes to the transition to a circular bioeconomy with an efficient and sustainable agrifood sector.

More information:

- $\quad$ http://www.acrres.nl/en/projecten_acrres/biobased-valorization-of-manure-and-digestate/

- Rommie van der Weide: rommie.vanderweide@wur.nl, +31320291631

- Hellen Elissen: hellen.elissen@wur.nl, +31320291223

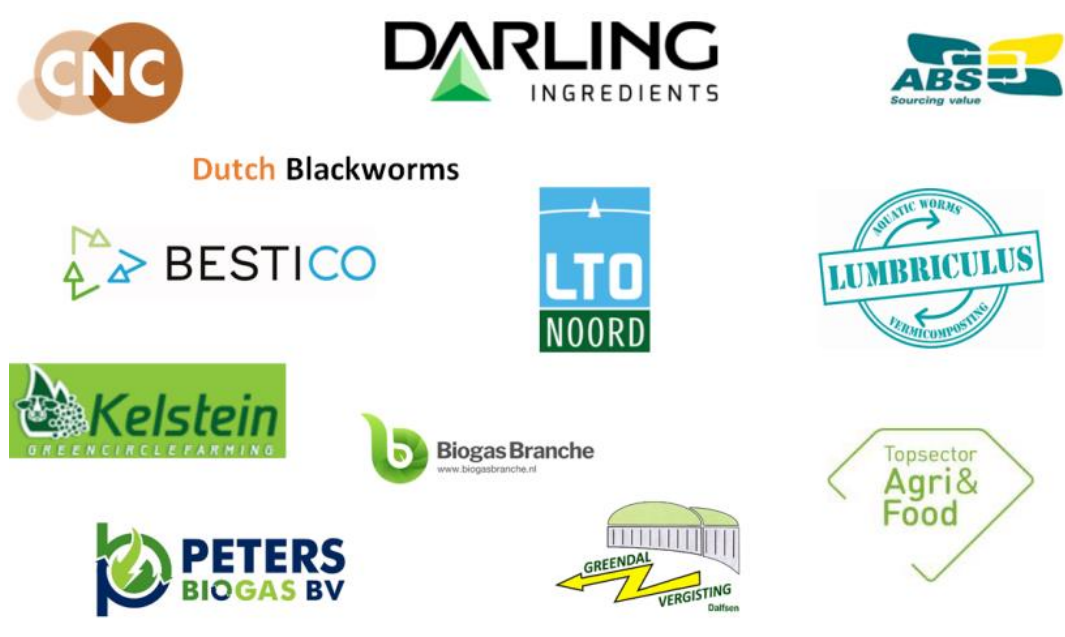




\section{Summary}

This report starts with a literature review on the topic. From literature it is known that fungi can selectively digest lignin, thereby releasing other components which may subsequently be easily converted into biogas during anaerobic digestion of normally recalcitrant compounds. In addition, several authors have found that commercial fungi can be grown on alternative substrates such as digestates. In the first experiment four substrates (flax shives, solid fractions of ACRRES digestate, Greendal digestate and cow manure) were incubated with 10 fungi species (Coprinus comatus, Ceriporiopsis subvermispora, Pleurotus ostreatus, Pleurotus eryngii, Lentinula edodes, Hypholoma frowardii, Clitocyba dusenii, Bjerkandera adusta, Hypholoma fasciculare, Gymnopilus sapineus and Kuehneromyces mutabilis). From the first experiment it became clear that most combinations of substrates and fungi resulted in growth/colonization, except for all combinations with Greendal digestate, probably due to fungicidal compounds. The most successful combinations were those with $P$. eryngii, $P$. ostreatus and $G$. Iucidum on ACRRES digestate, flax shives and cow manure, based on visual signs of fungal colonisation (air mycelium). Breakdown of recalcitrant compounds was not measured and the test was too short for fruiting bodies to develop, hence no conclusions can be drawn except that air mycelia of several fungi can develop on three of the four alternative substrates tested. In general, (average) biogas productions from the different substrates with or without fungal pretreatment were relatively low (35-73 $\mathrm{nm}^{3}$ biogas per ton product). When comparing the numbers to other data, biogas production from untreated flax shives was similar to that of straw and that of cow manure was somewhat lower than numbers found by other authors. Although data suggested a slight positive effect on biogas production in some cases, fungal pre-treatment of the solid fraction of cow manure with $P$. ostreatus, $P$. eryngii and $G$. lucidum did not lead to significantly increased biogas production. Also, fungal pretreatment of flax shives did not lead to increased biogas production with $P$. eryngii and G. lucidum and even to a significantly lower biogas production with $P$. ostreatus. In conclusion, fungal pretreatment of the solid fraction of cow manure and shives with $P$. ostreatus, $P$. eryngii and G. lucidum does not seem suitable to significantly increase biogas production from these substrates. 


\section{Introduction}

This report details two experiments: one for testing the growth of several (commercial) fungi on cow manure, digestates (biogas slurries) and shives, one for testing the effect of fungal pre-treatment on biogas production from cow manure and shives.

\subsection{Mushroom production on digestates (biogas slurry) and shives}

Substrate for mushroom production is often called 'compost'. The button (or common) mushroom (Agaricus bisporus) is traditionally cultivated on a composted mixture of straw, chicken and horse manure (depending on local availability of these resources). The common oyster mushroom Pleurotus ostreatus is cultivated on wheat straw or sawdust. Anaerobically digested waste contains fibrous components, a high $\mathrm{N}$ content and a high $\mathrm{pH}$, which is favorable for common mushroom cultivation (Jasinska et al, 2016). Also, the residual heat produced during anaerobic digestion could be used for steam production (Stoknes et al, 2013). As such, it's interesting to test the suitability of digestates for mushroom production and over the years several types have been investigated. Stoknes et al (2013) tested growth of Agaricus bisporus and Agaricus subrufescens in bag experiments on composts with food waste digestate as an ingredient, substituting chicken manure. They concluded that digestate could successfully substitute chicken manure without affecting the yield or several mushroom characteristics. Jasinska et al (2016) describe growth of three mushroom species (Agaricus arvensis, $A$. bitorquis and $A$. subrufescens) on a mixture of waste paper as $C$ source and (dewatered source separated household food waste) digestate as $\mathrm{N}$ source. They found that the composted straw/paper/digestate substrate was suitable as N source for some mushrooms. In another paper (Jasinska et al, 2017) they describe growth of Coprinus comatus, Ganoderma lucidum, Agaricus subrufescens and Laetiporus sulphureus on agar media prepared with the solid fraction of food waste digestate. They concluded that digestate could be applied as medium component for mushroom mycelia production or as a component of mushroom cultivation substrate. Zhou et al (2018) tested growth of Pleurotus ostreatus on digestate from chicken manure/straw and concluded that it could partially replace traditionally used cottonseed hulls, which has financial benefits. Adding a low percentage of digestate resulted in improved nutritional quality of the mushrooms.

Next to digestate, other low-cost waste streams can be interesting as mushroom substrate: Siwulski et al (2010) tested growth of $P$. ostreatus strains on alternative materials such as alder sawdust, rye straw, hemp and flax shive. They found that with flax shive the best mycelium growth was achieved. Although several alternative substrates are suitable for mushroom production, their year-round bulk availability and cost-efficient logistics are essential conditions for large-scale mushroom substrate production (Baars, 2020). 


\subsection{Biogas production from different substrates}

Cow manure constitutes 45\% of all livestock waste (Qiao et al, 2011) and can be used for biogas production, but the yield is relatively low compared to other waste streams (Table 1).

Table 1 Biogas and methane production from different wastes (From: Qiao et al, 2011)

\begin{tabular}{llll}
\hline & \multicolumn{3}{l}{ Raw materials } \\
\cline { 2 - 4 } & $\begin{array}{l}\text { Biogas } \\
\text { (mL/g-VS) }\end{array}$ & $\begin{array}{l}\text { Methane } \\
\text { content }(\%)\end{array}$ & $\begin{array}{l}\text { Methane } \\
(\mathrm{mL} / \mathrm{g}-\mathrm{gS})\end{array}$ \\
\hline Cow manure & 182.0 & 66.6 & 139.8 \\
Pig manure & 385.0 & 65.9 & 253.8 \\
Sludge & 202.0 & 76.9 & 155.5 \\
Fruit/vegetable waste & 443.0 & 63.4 & 280.9 \\
Food waste & 781.0 & 68.0 & 531.3 \\
\hline
\end{tabular}

Wróbel-Kwiatkowska et al (2015) found that biogas production from genetically modified flax shives (a waste product from processing flax fibres) was improved compared to that from unmodified shives. This was due to a reduced lignin content in the modified shives leading to modified cellulose crystallinity, thereby improving fermentation of the shives and optimizing biogas production. Alkalization (treatment with $\mathrm{NaOH}$ ) also led to increased biogas production. For both streams, fungal pre-treatment may lead to improved biogas production, due to extra conversion of lignocellulosic compounds.

In a previous publication Elissen et al (2019) found biogas production from champost (SMS = spent mushroom substrate) to be quite low. This can be due to high salt and ash contents. Alternatively it can be caused by shielding of residual cellulose by lignin. In champost, all easily degradable cellulose has been used for mushroom production. Next to this, there is residual hemicellulose present in champost, but this hemicellulose is heavily substituted with arabinosyl residues and glucuronic acid substituents. This makes this residual hemicellulose difficult to degrade by A. bisporus (Jurak, 2015). The question is whether the micro-organisms present in a digester able to handle that kind of hemicellulose.

\subsection{Pre-treatment of anaerobic digester substrates}

For efficient biodigester operation, the biodegradability of components in substrates is very important. The most easily degradable components for biogas production are simple carbohydrates (starch and sugars), followed by lipids \& proteins, complex carbohydrates (crops high in fibres) and complex polymers (cellulose, hemicellulose and lignin $^{1}$ ) (De Groene Rekenkamer, 2015). The latter plant polymers, specifically cellulosic compounds for example present in manure, limit the hydrolysis step in methane production (e.g. Yildirim et al, 2017). Monlau et al (2012) describe that lignin content is negatively correlated to BMP (biochemical methane potential), followed by soluble sugar content (positively correlated), protein content (positively correlated), crystalline cellulose content (negatively

\footnotetext{
${ }^{1}$ Cellulose is a crystalline, strong polysaccharide consisting of a linear chain of hundreds to thousands of linked glucose units $\left(\mathrm{C}_{6} \mathrm{H}_{10} \mathrm{O}_{5}\right)_{n}$. It's an important basic component of the primary cell wall of for example green plants and algae.

Hemicelluloses are heteropolymers (matrix polysaccharides like xylan), that contain different sugar monomers, e.g. glucose, xylose and mannose. They are part of the cell walls of plants where they bind with pectin to cellulose in a crosslinked fibres network. They have a random, amorphous, low-strength structure and are more readily hydrolysed than cellulose.

Lignins are cross-linked phenolic hydrophobic polymers with an amorphous structure. They are also important in the formation of cell walls of especially wood and bark, where they provide rigidity and resistance against bacterial attacks. Lignin-carbohydrate complexes are a limiting factor in the biodegradation of cellulose and hemicellulose.
} 
correlated) and amorphous (hemi)cellulose content (positively correlated). Figure 1 shows the process steps for the production of methane from lignocellulosic biomass ( $\mathrm{Xu}$ et al, 2019).

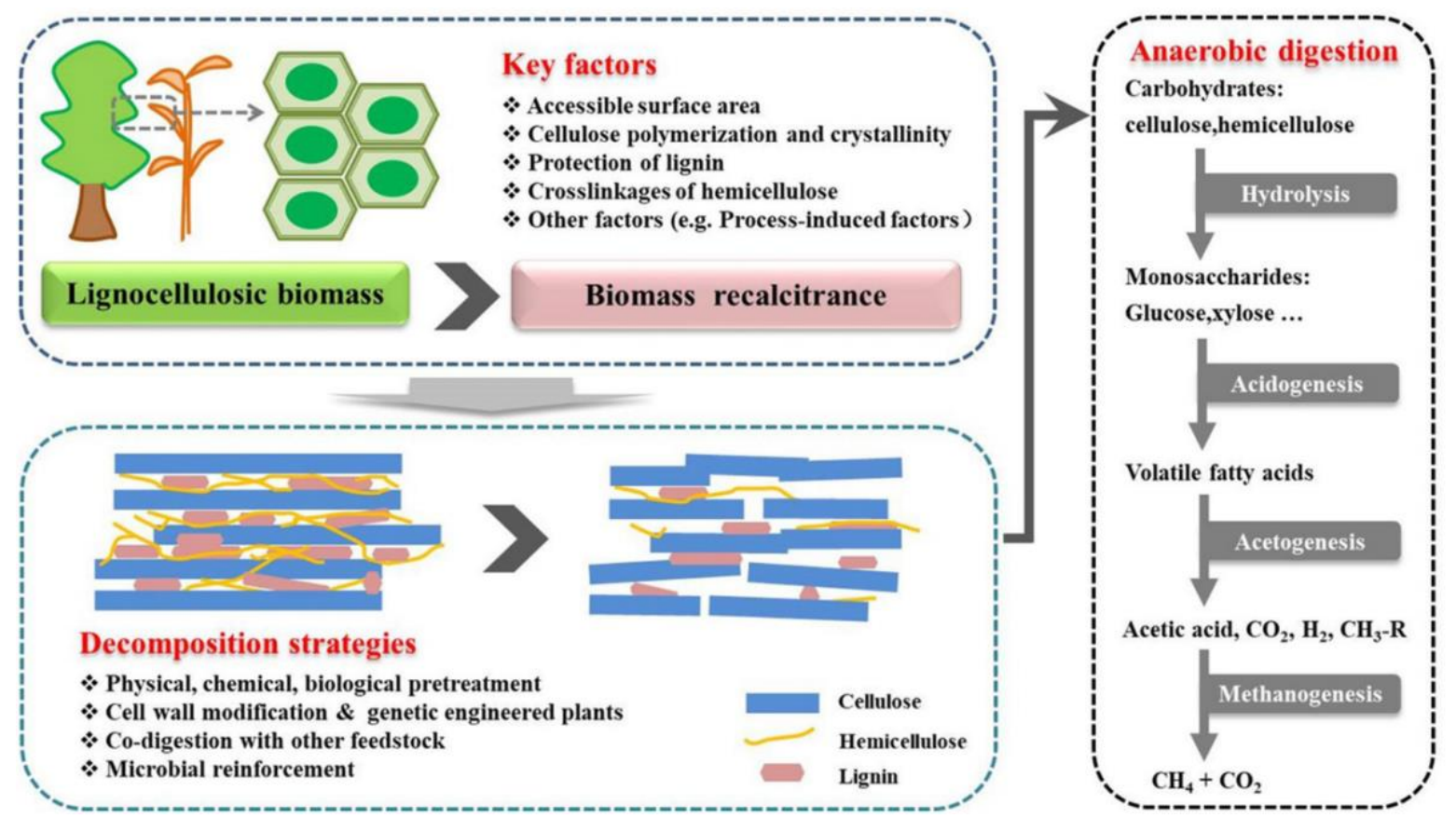

Figure 1 The bioconversion of lignocellulosic biomass to methane in four stages. Recalcitrance of lignocellulose restricts hydrolysis during the first stage and therefore pre-treatment is necessary for methane formation (Florian et al., 2013; Hagos et al., 2016). (Figure from: Xu et al, 2019).

Methods for improving biogas production can be physico-chemical, microbiological or a combination (Ali and Sun, 2015). Microbiological methods include bioaugmentation with bacteria or fungi. Fungi can degrade components that are not easily degradable for other living organisms by cellulolytic, hemicellulolytic, glycolytic, and proteolytic enzymes. Examples of fungi that have been used for pretreatment are Ceriporiopsis subvermispora, Auricularia auricula-judae, Trichoderma reesei,

Ischnoderma resinosum and Fomitella fraxinea (Ali \& Sun, 2015). Tuyen et al (2012) tested 11 whiterot fungi for their ability to degrade lignin and to improve fermentation of wheat straw in cow rumen, by measuring gas production. They found that some fungi degraded lignin with up to $63 \%$, but delignification was strongly correlated with the degradation of hemicellulose. As a result some fungi highly selective for lignin and not for cellulose were able to improve the nutritive value of wheat straw for cows. Gas production, as an indicator of improved digestibility, was positively correlated with the lignin/cellulose loss ratio. Several researches have investigated the addition of fungi for improving anaerobic digestion. Yildirim et al (2017) found improved biogas production from cow manure after addition of anaerobic rumen fungi (Orpinomyces sp., Piromyces sp., Anaeromyces sp., Neocallimastix frontalis), isolated from cows. According to the authors these fungi seem to be beneficial for methane formation from lignocellulosic components due to their non-specific extracellular ligninolytic enzymes. The addition of fungi resulted in improved biomass degradation, $60 \%$ higher biogas production and altered Archaeal and bacterial communities (more hydrogenotrophic methanogens). Ali and Sun (2015) pre-treated leaf waste and cow manure physico-chemically by milling, alkali addition for swelling of lignocelluloses and partially solubilising lignin, and pH adjustment. Subsequently, fungi (Aspergillus terreus and Trichoderma viride) were isolated from a biodigester fed with cow manure and food waste and used as fungal pre-treatment before anaerobic digestion of the wastes. The idea was that cellulose degradation would improve as a result. The authors concluded that methane yield improved with $30 \%$ by the combined pre-treatment. It is however not clear what part of the improved yield could be attributed to fungal pre-treatment. Xu et al (2019) added enzymatic pretreatment to fungal and microbiological methods for biological pre-treatment. Fungi have an oxidative lignolytic system (for degrading the phenyl bonds in lignin) and an hydrolytic enzyme system for breaking down (hemi-)cellulose. Carrere et al (2016) reviewed substrate pre-treatment strategies for improved anaerobic digestion on several scales. They concluded that for lignocellulosic biomass, the first goal should be delignification, followed by hemicellulose/cellulose hydrolysis, with alkali or 
biological (fungi) pre-treatments being the most promising. Lignocellulosic biomass can be degraded by white-, brown- and soft-rot fungi. White-rot fungi delignify biomass and are therefore the most investigated for pre-treatment. Fungal pre-treatments are carried out as aerobic solid-state fermentation processes requiring low reactor volumes and amounts of water. Fungal pre-treatment generally results in a significant increase in specific methane potential (compared to the original feedstocks); up to $50 \%$ and even higher in the case of feedstocks with very low initial biodegradability. However, organic matter losses (carbohydrate consumption by endogenous organisms (e.g. heterotrophic, non-methanogenic bacteria), usually 10-20\%) are not often mentioned and may lead to lower increases in specific methane potential. Nevertheless, this easily degradable organic matter can be used to allow the substrate to self-heat and as a result suppress the endogenous microflora and provide a head start for the fungal strain that one would like to introduce to selectively degrade lignin. Direct use of fungi prevents the extra step of extracting enzymes from them (mainly from the genus Aspergillus or Trichoderma, e.g. cellulase and xylanases), which as an addition has also been applied for increasing biogas production. Control parameters for applying fungal pre-treatment are fungi strains and exposure time. Strengths are low energy demand and scalability, while weaknesses are carbon losses and exposure time (weeks to months). Pečar et al (2019) studied pre-treatment of chicken manure/sawdust and barley straw by Pleurotus ostreatus and Trametes versicolor, before incubation in an anaerobic digester. The researchers found no effect of the fungal pre-treatment and concluded that these white-rot fungi were not suitable for increasing methane production from these substrates. Rouches et al (2016) wrote an extensive review on pre-treatment of lignocellulosic biomass by white-rot fungi. Figure 2 shows three scenarios for using fungi pretreatment for enhancing biogas production.

A

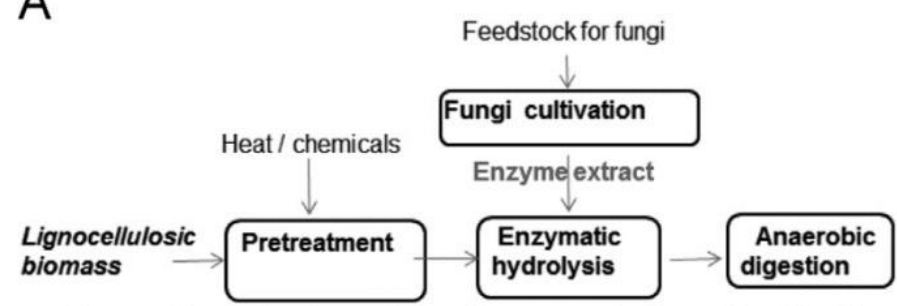

Enzymatic pretreatment based on second generation bioethanol process

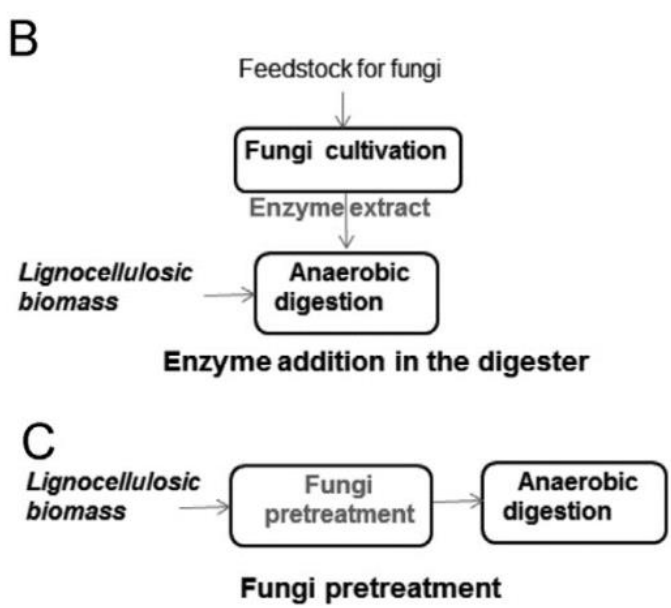

Figure 2 Three scenarios for combining enzymatic and fungal pre-treatment and anaerobic digestion of lignocellulosic biomass (Figure from: Rouches et al, 2016).

The authors also give a more detailed description of different types of fungi that are able to degrade lignocellulosic biomass.

- $\quad$ Soft-rot fungi (ascomycetes and deuteromycetes): degradation mechanisms are not well understood and they require substrates with a low lignin content

- Brown-rot fungi BRF (certain basidiomycetes): they degrade (hemi)-cellulose but modify lignin only to a limited extent

- White-rot fungi WRF (basidiomycetes and sometimes ascomycetes): these fungi are the most efficient in lignin degradation as their enzyme system can convert phenolic compounds into 
$\mathrm{CO}_{2}$. The quickest lignin degraders are basidiomycetes and some strains mostly use hemicellulose as carbon source which leads to small losses of cellulose only.

Disadvantages of WRF pre-treatment are, in addition to long incubation times mentioned before, the need for improved specific lignin degradation and colonization of the inoculum. In summary there is a general need for improved control of the fungal pre-treatment process. They also describe the different extracellular enzymes employed by WRF, such as hydrolases, lignin peroxidase (ligninase), manganese peroxidase and laccase (phenoloxidase), and their mode of action, which we will not discuss further. 


\section{Materials and methods}

\subsection{Growth of fungi on cow manure, digestates and shives}

Four substrates were tested in duplicate with ten types of fungi, which had been pre-incubated on sorghum. The substrates were the solid fraction of freshly separated cow manure, (flax) shives and the solid fractions of digestates from two different anaerobic digesters (more details in paragraph 2.2). ACRRES digestate originated from a digester fed with cow manure and nature grass, Greendal digestate originated from a digester mainly fed with pig manure. The fungi were Coprinus comatus, Ceriporiopsis subvermispora, Pleurotus ostreatus, Pleurotus eryngii, Lentinula edodes, Hypholoma frowardii, Clitocyba dusenii, Bjerkandera adusta, Hypholoma fasciculare, Gymnopilus sapineus and Kuehneromyces mutabilis. This is a variety of basidiomycete fungi of which Pleurotus eryngii and Coprinus comatus are litter degrading fungi. The other species are wood degrading species. As there is not much literature on the ability of wood rotting fungi to grow on manure or digestate, it is a rather random selection. This resulted in 40 combinations that were inoculated for four weeks each. DM content and wet weight were measured before and after incubation, $\mathrm{pH}$ at the start. The method followed is shown in Figure 3.

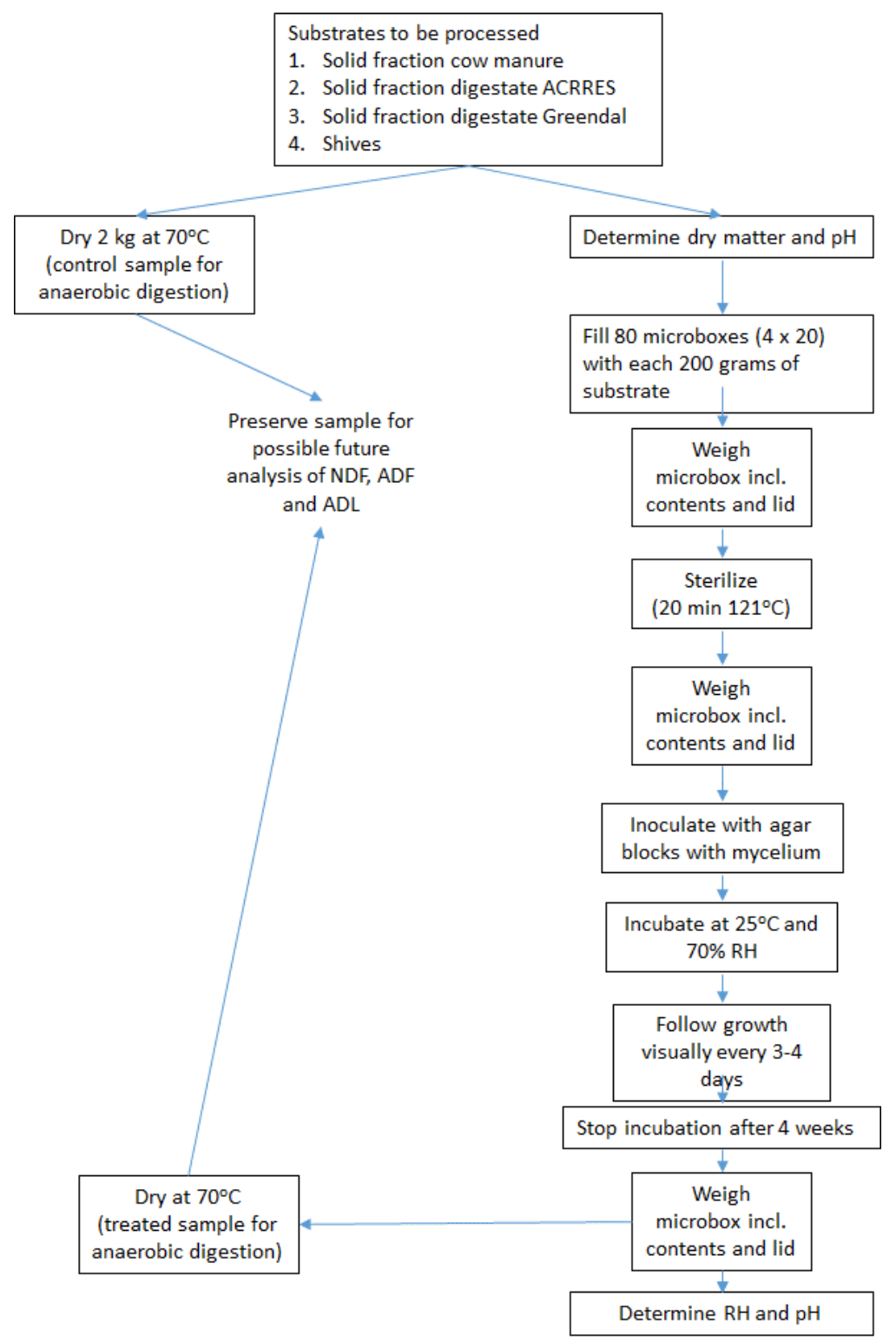

Figure 3 Description of method followed for incubating the substrates with fungi. 


\subsection{Input materials/fungi}

Three substrates and three fungi were selected (from the original four substrates and ten fungi previously incubated, see previous paragraph) for further lab-scale mesophilic anaerobic digestion tests. A fifth substrate, nature grass, was also incubated but did not result in fungal growth and therefore was left out of the anaerobic digestion tests.

1. Cow manure: the solid fraction of cow manure (Mts Winia, Oostrum, the Netherlands)

2. Shives: the wooden refuse removed during processing flax, as opposed to the fibres (Agribiosource, the Netherlands). Shives were moistened until water uptake capacity.

3. Insect frass: produced by $H$. illucens larvae on food industry residuals, obtained from Bestico (Berkel en Rodenrijs, the Netherlands) (incubated without fungi, as a check for earlier experiments by Elissen et al, 2019)

Dry matter percentage and $\mathrm{pH}$ before incubation were analysed (Table 2):

Table 2 Dry matter percentage and $\mathrm{pH}$ of the original four substrates before sterilization and incubation with fungi.

$\begin{array}{lll}\text { Test substrate } & \text { DM } \% & \text { PH } \\ \text { Cow manure } & 36.4 & 8.78 \\ \text { ACRRES digestate } & 22.5 & 8.97 \\ \text { Greendal digestate } & 30.1 & 8.94 \\ \text { Shives } & 37.6 & 7.72\end{array}$

Subsequently, cow manure and shives were sterilized and incubated with three fungi species: Pleurotus ostreatus (common oyster mushroom, Po), Pleurotus eryngii (king trumpet mushroom, French horn mushroom, king oyster mushroom, king brown mushroom, Pe) and Ganoderma lucidum (reishi mushroom or lingzhi, Gl). The first two species are edible species, the latter a medicinal species. Each fungus had been grown in a number of replicate microboxes of $1200 \mathrm{ml}$ volume with 200 gram of substrate. After colonisation all microboxes were mixed to prepare a mix sample for the digester tests. The method followed was the same as in Figure 3 but no mass balance was created. Average dry and organic matter content are shown in Table 3. $\mathrm{pH}$ values after incubation/ before anaerobic digestion tests were always between 7.8 and 7.9 and after anaerobic digestion tests between 7.4 and 7.8 (Annex I).

Table 3 Average dry matter and organic matter percentages of input materials with or without fungal additions before anaerobic digestion. $I=$ insect frass, $M=$ cow manure solid fraction, $S=$ shives, $P o=$ Pleurotus ostreatus, $P e=$ Pleurotus eryngii, $G l=$ Ganoderma lucidum. ${ }^{1)} n=1{ }^{2)} n=2{ }^{3)}$ $n=3$. $n$ represents the number of boxes

\begin{tabular}{lll} 
Test & DM & OM \\
substrate & $\%$ ww & $\%$ DM \\
\hline $\mathbf{I}^{\mathbf{1}}$ & 52.5 & 89.5 \\
\hline $\mathbf{M}^{\mathbf{3})}$ & $33.3 \pm 0.8$ & $85.0 \pm 0.5$ \\
\hline $\mathbf{M ~ P o}^{\mathbf{3})}$ & $31.3 \pm 1.0$ & $83.4 \pm 0.5$ \\
\hline $\mathbf{M ~ P e}^{\mathbf{2}}$ & $33.4 \pm 0.1$ & $85.2 \pm 0.1$ \\
\hline $\mathbf{M ~ G l}^{\mathbf{3})}$ & $31.7 \pm 0.5$ & $84.2 \pm 0.3$ \\
\hline $\mathbf{S ~}^{\mathbf{1}}$ & 28.7 & 87.8 \\
\hline $\mathbf{S ~ P o}^{\mathbf{1}}$ & 25.8 & 87.2 \\
\hline $\mathbf{S ~ P e}^{\mathbf{1}}$ & 25.4 & 87.0 \\
\hline $\mathbf{S ~ G l}^{\mathbf{1}}$ & 23.0 & 84.2 \\
\hline
\end{tabular}




\subsection{Anaerobic digestion tests}

The anaerobic digestion tests were performed by Opure (Ede, the Netherlands). Individual test substrates were incubated in triplicate tests according to Table 4.

Table 4 Test durations of anaerobic digestion tests $(n=3) . I=$ insect frass, $M=$ cow manure solid fraction, $S=$ shives, $P o=$ Pleurotus ostreatus, $P e=$ Pleurotus eryngii, $G l=$ Ganoderma lucidum.

\begin{tabular}{lc} 
Substrate & Duration (days) \\
\hline I & $\mathbf{5 3}$ \\
\hline M & $\mathbf{5 5 - 6 4}$ \\
\hline M Po & $55-65$ \\
\hline M Pe & $63-65$ \\
\hline M Gl & $55-63$ \\
\hline S & $\mathbf{5 5}$ \\
\hline S Po & 62 \\
\hline S Pe & 60 \\
\hline S Gl & 60
\end{tabular}

Pre-treated digestates were used as seed material for the tests. The structure had to be as homogeneous as possible for an equal distribution over the test vessels, with as low biogas formation and as many different bacteria as possible. This was achieved by using three different digestates from low-loaded systems, which were pre-processed (e.g. coarse parts were sieved out). As mentioned, the seed digestates should produce as little gas as possible, otherwise the measurement would be inaccurate (biogas production was measured as the difference between vessels with only seed digestates and vessels with seed digestates plus added test substrates, both in triplicate). 200 grams of seed digestates and 1.3-3.1 grams of test substrate (Annex 2) were added to $1.2 \mathrm{~L}$ vessels. The dosages of the test substrates were based on predetermined loads to obtain the right amount of biogas production and were based on organic matter content of the substrates: substrates with lower organic matter contents were dosed at higher concentrations. DM and OM were determined in all the substrates prior to the tests. $\mathrm{pH}$ values were determined at the start and end of the tests in each vessel for the total mixtures. In each vessel a stirrer was added and they were flushed with nitrogen and closed. The vessels were put in an incubator at $35^{\circ} \mathrm{C}$ and stirred only once a week briefly). Biogas production was determined by measuring gas pressure and analysing gas composition, after which results were converted to standard $\mathrm{m}^{3}\left(\mathrm{~nm}^{3}\right)$ biogas (= differences in yield between reference (seed digestates only) and substrate vessels). Tests were terminated when net biogas formation was zero.

\subsection{Statistical analyses}

We analysed the relationship between biogas production (in its different measured forms: biogas production in $\mathrm{nm}^{3}$ biogas per ton product, specific biogas production in $\mathrm{nm}^{3}$ biogas per ton $\mathrm{DM}$ or $\mathrm{kg}$ $\mathrm{OM}$, methane production in $\mathrm{nm}^{3} \mathrm{CH}_{4}$ per ton product, specific methane production in $\mathrm{nm}^{3} \mathrm{CH}_{4}$ per ton $\mathrm{DM}$ or $\mathrm{kg} \mathrm{OM}$ ) and different substrates and fungi in the framework of a multiple linear regression model (all assumptions of the model were met). Analyses of variance revealed that the final model includes the interaction of substrate and fungi in all cases. Pairwise comparisons between the different substrate-fungi combinations were performed based on the estimated marginal means with a Tukey adjustment. All statistical analyses were conducted using R software version 3.6.0 (mainly with the "Im" framework and the library "emmeans"). 


\section{$3 \quad$ Results}

\subsection{Growth of fungi on different substrates}

The growth substrates resulted in different growth patterns of the fungi. Pleurotus ostreatus and Pleurotus eryngii were found to be the most consistent in their abilities to colonize the substrates. Also, both fungi are effective in breaking down lignin. Good growth was found on ACRRES digestate, the solid fraction of cow manure and shives. Figures 4 and 5 show growth of $P$. ostreatus and $P$. eryngii respectively on the different substrates. Clearly, Greendal digestate impaired visible fungal growth. Fungal growths on cow manure, ACRRES digestate and shives were very similar.
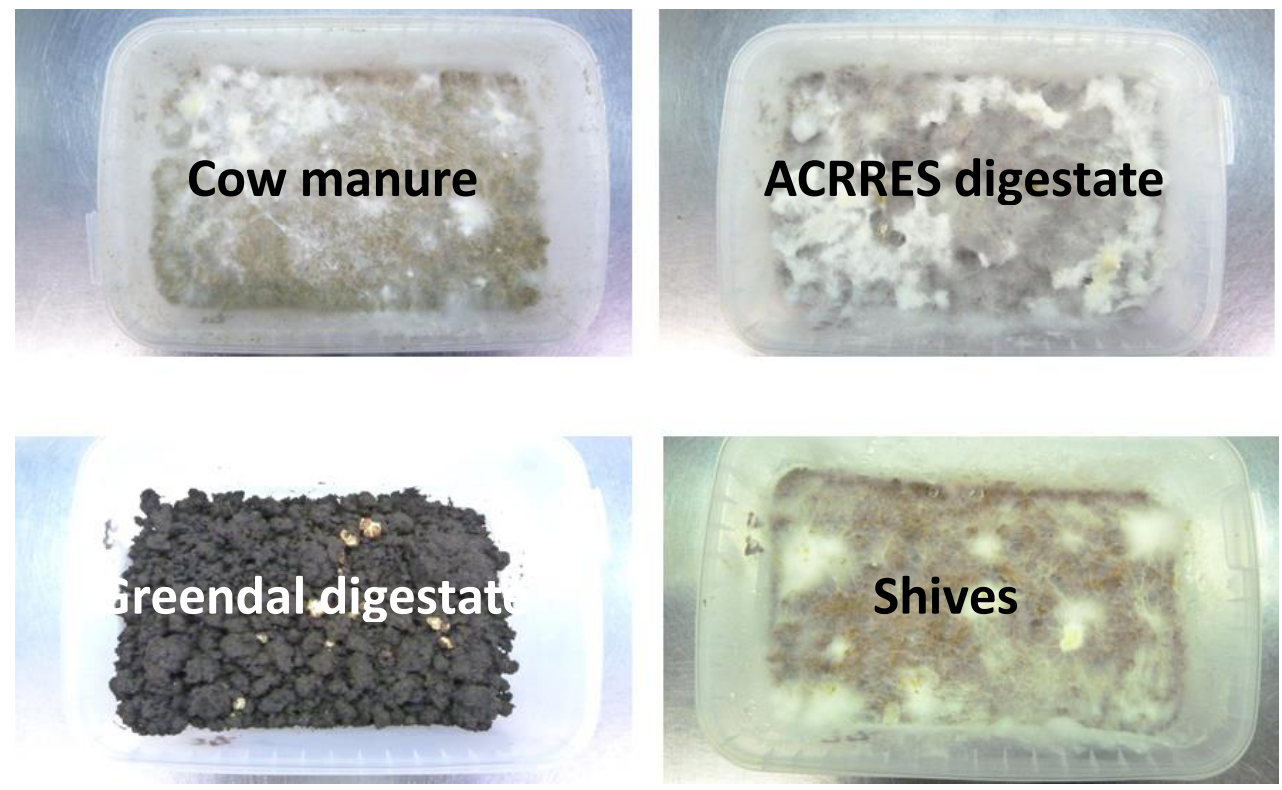

Figure 4 Growth of Pleurotus ostreatus after 4 weeks on cow manure, ACRRES digestate, shives and Greendal digestate.
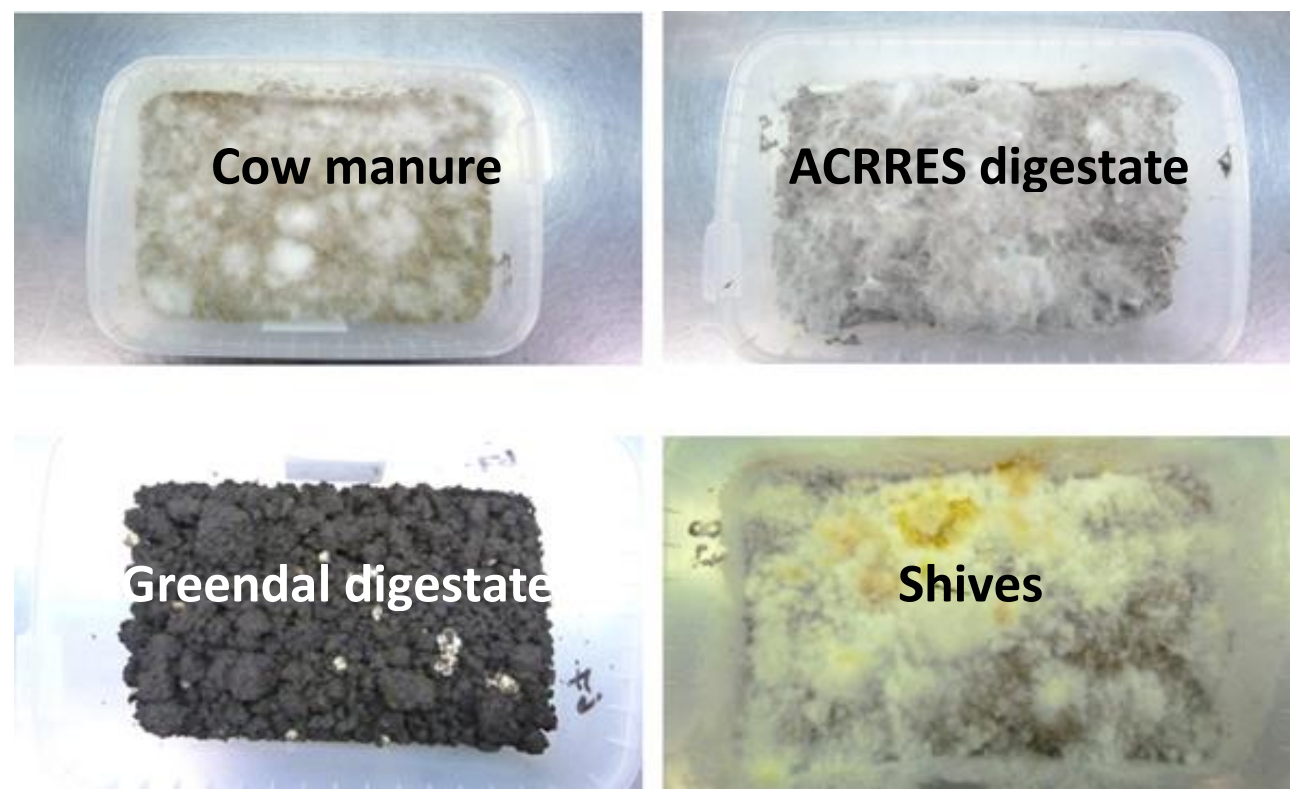

Figure 5 Growth of Pleurotus eryngii after 4 weeks on cow manure, ACRRES digestate, shives and Greendal digestate. 
A summary of all growth results is shown in Annex 1. Dry matter breakdown in the different combinations and visual impressions are shown in Figures 6 (cow manure), 7 (Greendal digestate), 8 (flax shives) and 9 (ACRRES digestate).

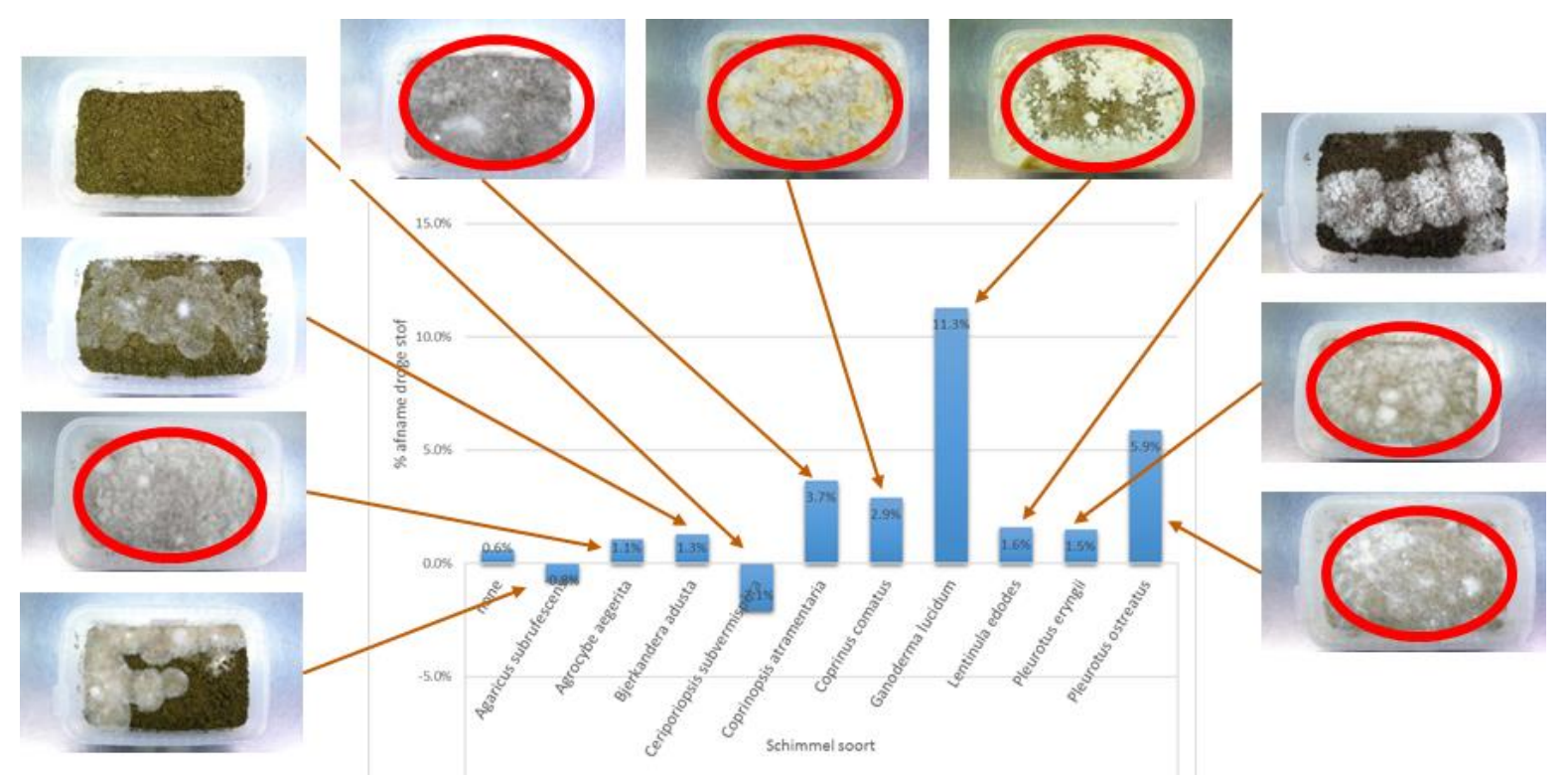

Figure 6 Colonization of the solid fraction of cow manure by 10 fungi: Dry matter breakdown and visual impression after 4 weeks. Red ovals mark selected combinations.

From cow manure the following fungi were selected for further analysis based on thorough colonization: Agrocybe aegerita, Coprinopsis atramentaria, Coprinus comatus, Ganoderma lucidum, Pleurotus eryngii and Pleurotus ostreatus

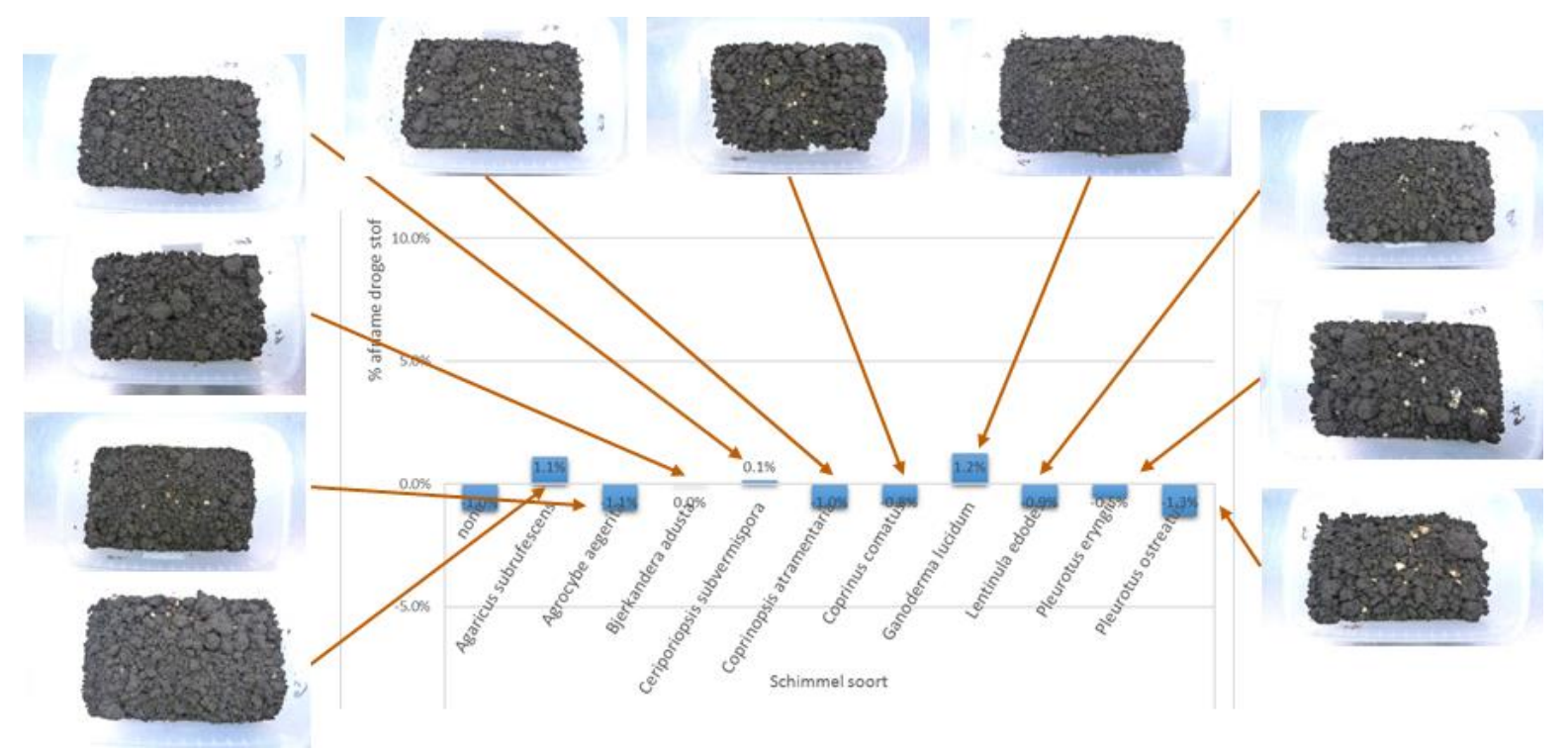

Figure 7 Colonization of Greendal digestate by 10 fungi: Dry matter breakdown and visual impression after 4 weeks. Red ovals mark selected combinations.

No fungi were selected from Greendal digestate. 


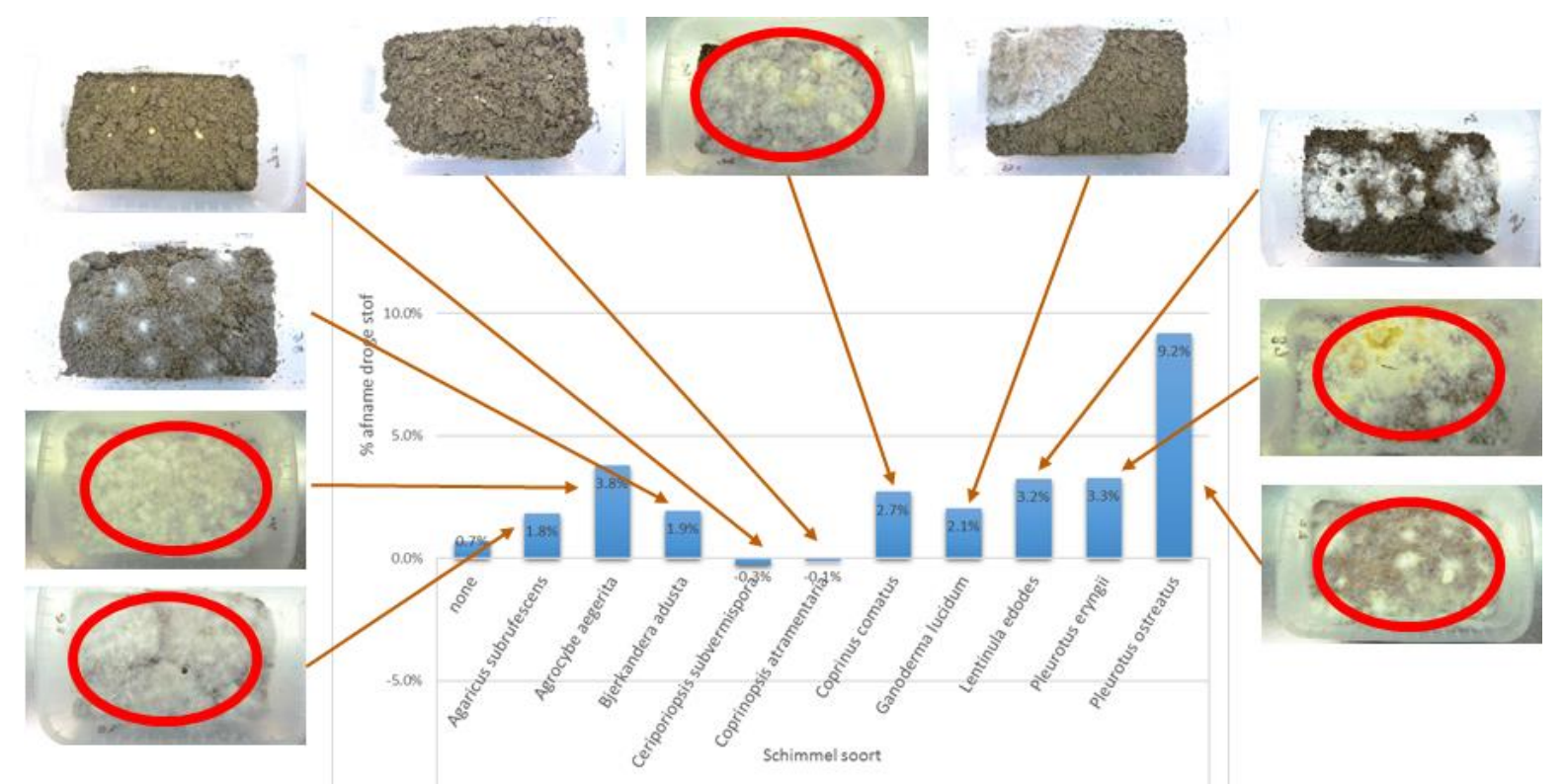

Figure 8 Colonization of flax shives by 10 fungi: Dry matter breakdown and visual impression after 4 weeks. Red ovals mark selected combinations.

From flax shives the following fungi were selected for further analysis based on thorough colonization: Agaricus subrufescens, Agrocybe aegerita, Coprinus comatus, Pleurotus eryngii and Pleurotus ostreatus.

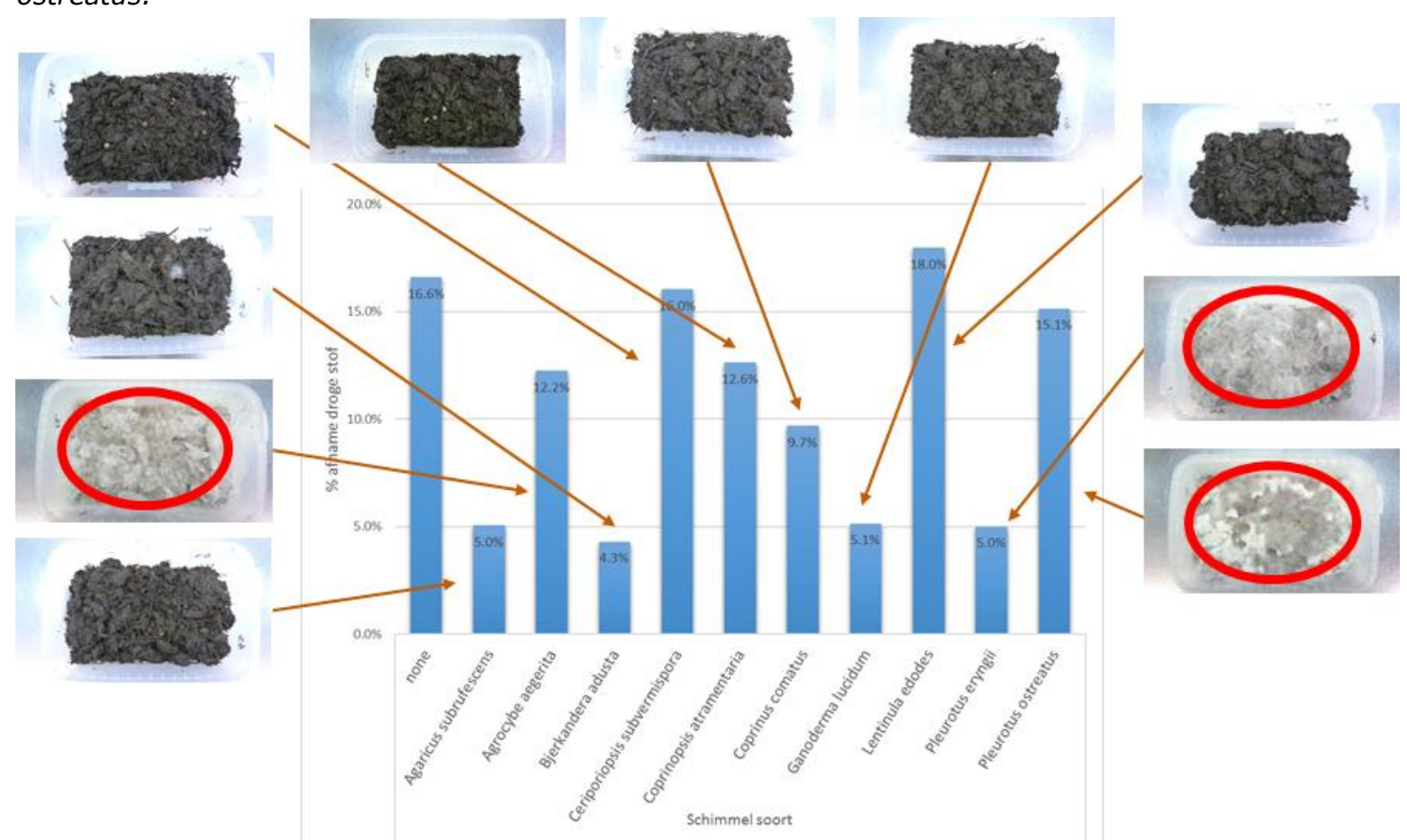

Figure 9 Colonization of ACRRES digestate by 10 fungi: Dry matter breakdown and visual impression after 4 weeks. Red ovals mark selected combinations.

From ACRRES digestate the following fungi were selected for further analysis based on thorough colonization: Agrocybe aegerita, Pleurotus eryngii and Pleurotus ostreatus.

In all four substrates, the degree of visual fungal overgrowth did not seem to be positively correlated to the degree of dry matter breakdown. In addition, in the ACRRES digestate control (as opposed to the other three substrates), dry matter breakdown was very high ( $16 \%$ ). We have no explanation for this.

From the selected 14 combinations finally the three most successful fungi were selected for testing as pre-treatment of cow manure and shives for biogas production: Pleurotus ostreatus, Pleurotus eryngii and Ganoderma lucidum. 


\subsection{Biogas production and quality}

Biogas productions in time in manure and shives substrates per ton test substrate are shown in Figures 10 and 11 respectively. Each line represents 1 test box and is an average of three technical replicates (subsamples from one box). The control measurements with cow manure were repeated a second time ('new'). The average standard deviation between the final biogas production (in $\mathrm{nm}^{3}$ biogas/ton substrate) within the triplicates was $3.7 \% \pm 2.1 \%$ of the total, which means that there was little variation between the technical replicates.

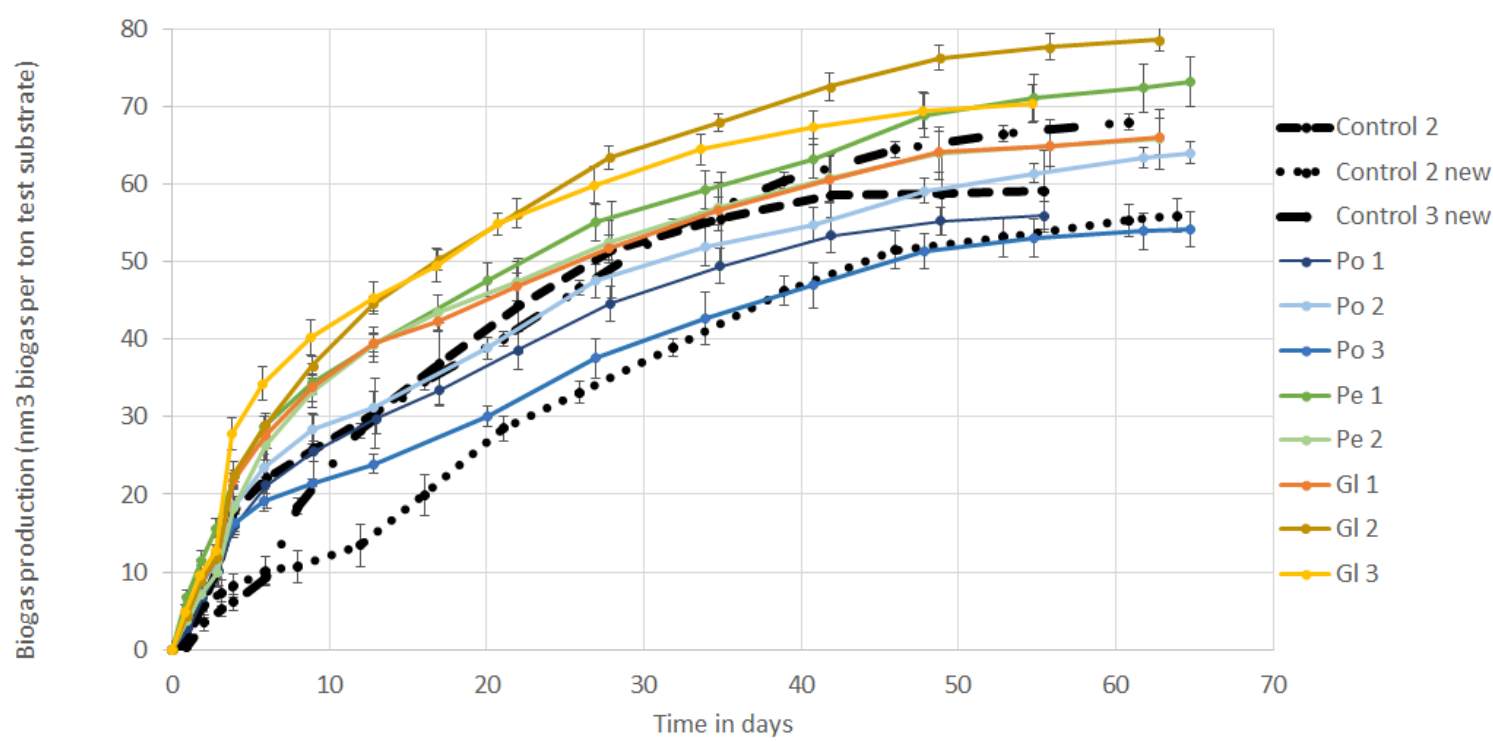

Figure 10 Biogas production of the manure substrates $(n=3)$. Po = Pleurotus ostreatus, $P e=$ Pleurotus eryngii, GI = Ganoderma lucidum. 1, 2 and 3 represent the box numbers, 'new' represents a later (repeated) incubation of the manure controls, which was performed due to technical problems

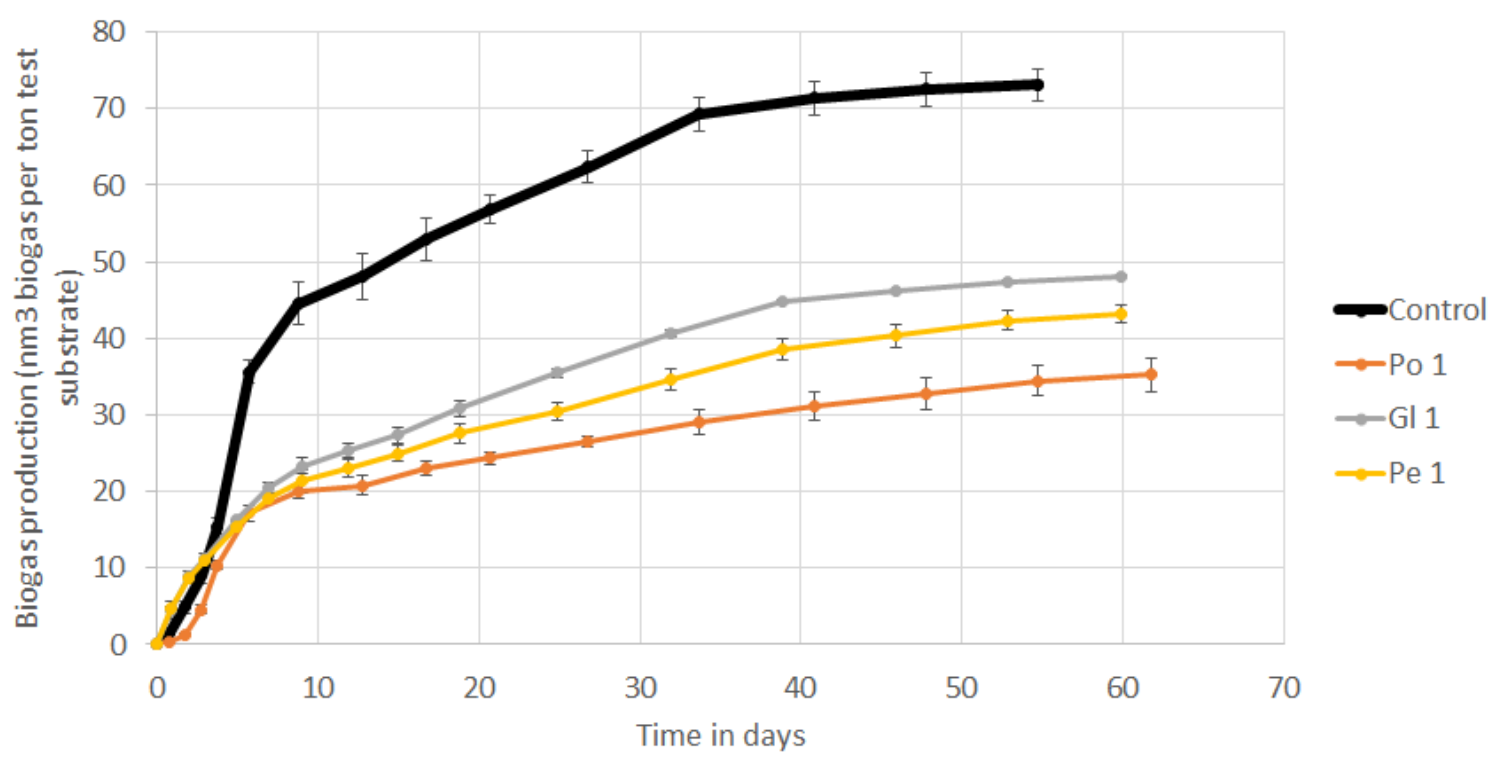

Figure 11 Biogas production of the shives substrates $(n=3)$. Po = Pleurotus ostreatus, $P e=$ Pleurotus eryngii, Gl = Ganoderma lucidum. 1 represents the box number

Figure 10 shows that, in comparison to the control, cow manure treated with $P$. ostreatus seemed to show slightly lower biogas productions. Cow manure treated with $P$. eryngii and $G$. lucidum overall seemed to lead to higher biogas productions than the controls, with the latter showing the highest 
effect. Also, the biogas production rate with some fungi seemed higher than the controls in the initial trial period. The variation between the three cow manure controls was however large. For shives (Figure 11), the effect was very different: all three treatments with fungi seemed to lead to lower biogas productions. Table 5 shows average biogas and methane productions on total product basis and data on biogas quality.

Table 5 Measured average biogas and methane productions on total product basis and biogas qualities ( \pm standard deviations). $I=$ insect frass, $M=$ cow manure solid fraction, $S=$ shives, $P o=$ Pleurotus ostreatus, $P e=$ Pleurotus eryngii, $G l=$ Ganoderma lucidum. ${ }^{1)} n=1^{2)} n=2{ }^{3)} n=3$

\begin{tabular}{|c|c|c|c|}
\hline Addition & $\begin{array}{l}\text { Biogas } \\
\text { (nm } \mathrm{nm}^{3} \text { ton prod.) }\end{array}$ & $\begin{array}{l}\mathrm{CH}_{4} \\
\left(\mathrm{~nm}^{3} / \text { ton prod. }\right)\end{array}$ & $\begin{array}{l}\text { Biogas quality } \\
\% \mathrm{CH}_{4}\end{array}$ \\
\hline I 1) & 274 & 159 & 58.2 \\
\hline $\mathbf{M}^{3)}$ & $61 \pm 7$ & $33 \pm 3$ & $54.2 \pm 1.3$ \\
\hline $\mathrm{MPo}{ }^{3)}$ & $58 \pm 5$ & $30 \pm 3$ & $52.1 \pm 0.9$ \\
\hline $\mathrm{MPe}{ }^{2)}$ & $69 \pm 5$ & $38 \pm 3$ & $54.2 \pm 0.7$ \\
\hline M Gl ${ }^{3)}$ & $72 \pm 6$ & $38 \pm 3$ & $52.7 \pm 0.1$ \\
\hline $\mathbf{S}^{1)}$ & 73 & 43 & 59.0 \\
\hline $\mathrm{S} \mathrm{Po}^{1)}$ & 35 & 21 & 58.5 \\
\hline $\mathrm{SPe}{ }^{1)}$ & 43 & 24 & 56.3 \\
\hline S Gl ${ }^{1)}$ & 48 & 27 & 55.5 \\
\hline
\end{tabular}

Biogas qualities ranged from 52-59\% and showed no clear differences (no statistical analysis), except that methane content was slightly lower in the treated streams. Biogas production was highest for insect frass, followed by (treated) manure and (treated) shives (see also Figures 10 and 11). The same was true for methane production per ton product, as biogas quality showed only minor differences. Final biogas and methane productions were plotted on dry matter (Figure 12) and organic matter basis (Figure 13).

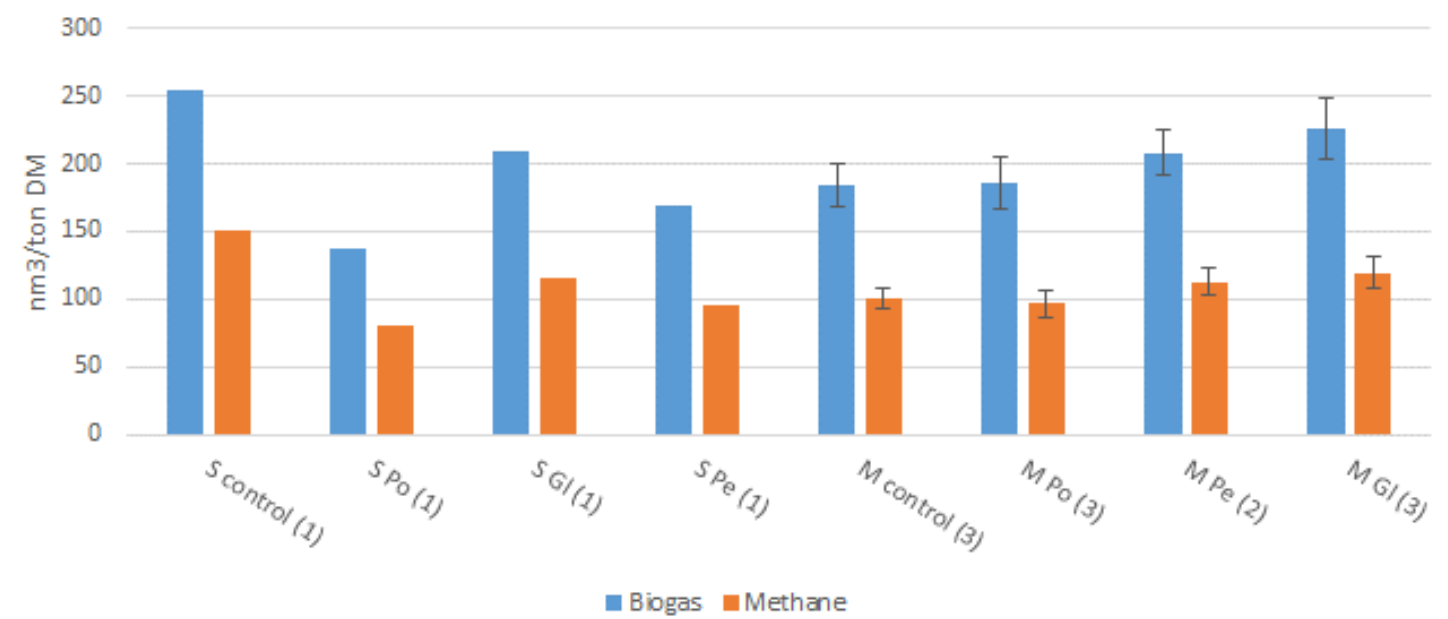

Figure 12 Average production of biogas and methane per ton DM (no. of boxes between bars). M= cow manure solid fraction, $S=$ shives, Po = Pleurotus ostreatus, Pe = Pleurotus eryngii, $G I=$ Ganoderma lucidum. Standard deviations are only shown for combinations that were tested in multiple boxes. 


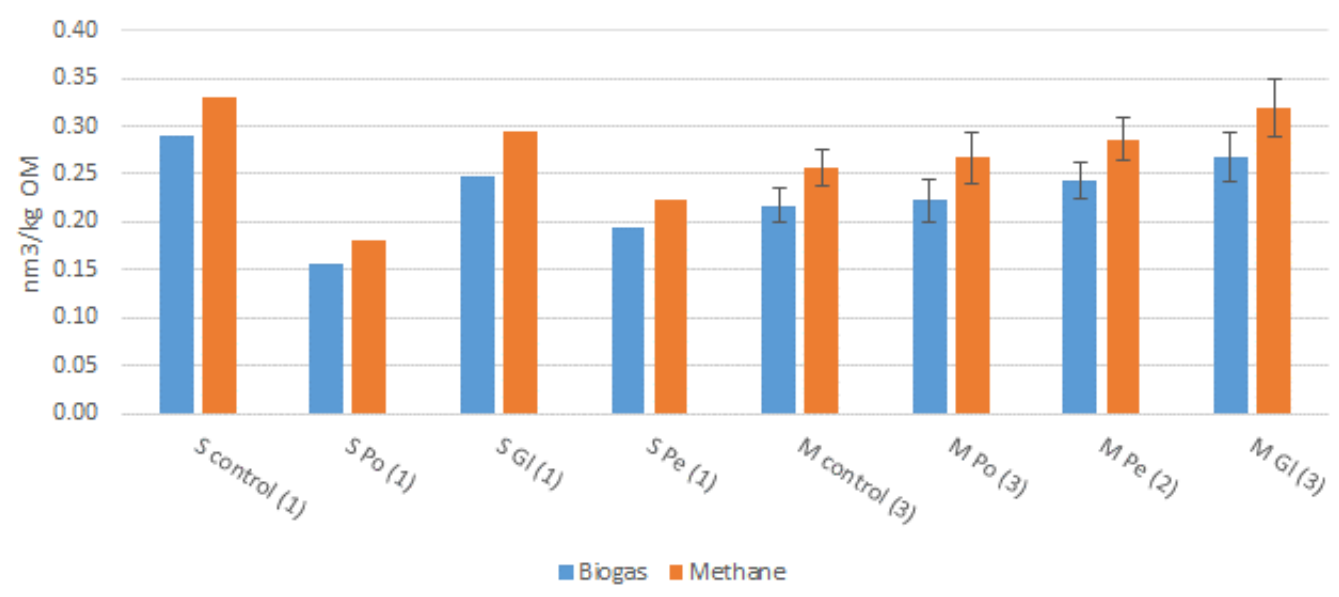

Figure 13 Average production of biogas and methane per $\mathrm{kg}$ OM (no. of replicates between bars). $M=$ cow manure solid fraction, $S=$ shives, $P o=$ Pleurotus ostreatus, $P e=$ Pleurotus eryngii, $G l=$ Ganoderma lucidum. Standard deviations are only shown for combinations that were tested in multiple boxes.

A statistical analysis was performed: The relationship between the variables (final) biogas or methane production (on product, dry matter and organic matter basis) was statistically evaluated as well as the different fungi and substrates. A linear model was used with biogas production as response variable and fungus, substrate and interaction fungus/substrate as independent variables. With this interaction we describe that the fungi acted differently on different substrates. We performed model comparisons to determine which model was most suitable (one main effect, two main effects, main effects with interaction). The tests came to the conclusion that the interaction always has to be regarded as significant. In addition, pairwise comparisons (with multiple testing corrections) were made to establish which combinations of fungus/substrate showed significant differences between each other (28 comparisons). Table 6 shows which combinations are significantly different from each other.

Table 6 Statistical results for different combinations of substrates and fungi. $M=$ cow manure solid fraction, $S=$ shives, $P o=$ Pleurotus ostreatus, $P e=$ Pleurotus eryngii, $G l=$ Ganoderma lucidum.

\begin{tabular}{|c|c|c|c|c|}
\hline & Data & Estimate & SE & p-value \\
\hline biogasprod_nm3 ( $\mathrm{nm}^{3}$ biogas/ ton product) & Table 5 & & & \\
\hline S control - S Po & & 37.851 & 8.477 & 0.034 \\
\hline $\mathrm{M} \mathrm{Gl}-\mathrm{S} \mathrm{Pe}$ & & 28.538 & 6.922 & 0.049 \\
\hline M GI - S Po & & 36.390 & 6.922 & 0.014 \\
\hline M Pe - S Po & & 34.190 & 7.341 & 0.027 \\
\hline spec_biogasprod_nm3_DM ( $\mathrm{nm}^{3}$ biogas/ ton DM) & Figure 12 & & & \\
\hline S control - S Po & & 118.076 & 26.655 & 0.035 \\
\hline spec_biogasprod_nm3_OM ( $\mathrm{nm}^{3}$ biogas/ kg OM) & Figure 13 & & & \\
\hline S control - S Po & & 0.133 & 0.031 & 0.040 \\
\hline M GI - S Po & & 0.111 & 0.025 & 0.036 \\
\hline CH4_prod_nm3 ( $\mathrm{nm}^{3}$ methane/ ton product) & Table 5 & & & \\
\hline $\mathrm{S}$ control - S Pe & & 18.864 & 4.534 & 0.047 \\
\hline S control - S Po & & 22.491 & 4.535 & 0.020 \\
\hline M GI - S Po & & 17.141 & 3.7024 & 0.028 \\
\hline M Pe - S Po & & 17.015 & 3.9269 & 0.039 \\
\hline spec_CH4_prod_nm3_DM $\left(\mathrm{nm}^{3}\right.$ methane/ ton DM $)$ & Figure 12 & & & \\
\hline M control - S control & & -50.335 & 11.626 & 0.039 \\
\hline S control - M Po & & 53.564 & 11.626 & 0.029 \\
\hline S control - S Po & & 70.282 & 14.238 & 0.020 \\
\hline spec_CH4_prod_nm3_OM ( $\mathrm{nm}^{3}$ methane/ kg OM) & Figure 13 & & & \\
\hline S control - S Po & & 0.151 & 0.0358 & 0.045 \\
\hline M GI - S Po & & 0.138 & 0.0292 & 0.025 \\
\hline
\end{tabular}


For all responses a significant difference between the shives control and shives treated with $P$. ostreatus was found: Figure 11 shows that a significantly lower biogas production was found in the treated substrate. In addition, for some responses a significant difference was found between manure treated with $G$. lucidum and shives treated with $P$. ostreatus. For the responses per ton product a significant difference between manure treated with $P$. eryngii and shives treated with $P$. ostreatus was also found. It seems that within the manure substrate no significant differences between fungi treated samples and the control can be found, based on the data used for the analysis. Within the shives substrate however, some significant differences could be found. Within the fungi no significant differences could be found except for one response for the controls.

\subsection{Organic matter breakdown}

In addition to biogas production also the organic matter breakdown as well as the net residual/nondigestible/non-fermentable material fraction were calculated (Table 7).

Table 7 Non-digestible fraction in $\mathrm{kg}$ DM/ton and organic matter breakdown percentages for all the substrates (averages with standard deviations). $I=$ insect frass, $M=$ cow manure solid fraction, $S$ = shives, $P o=$ Pleurotus ostreatus, $P e=$ Pleurotus eryngii, $G l=$ Ganoderma lucidum. ${ }^{1)} n=1{ }^{2)} n=2$ 3) $n=3$

\begin{tabular}{|c|c|c|}
\hline Substrate & $\begin{array}{l}\text { Non-digestible } \\
\text { (kg DM/ton) }\end{array}$ & $\begin{array}{l}\text { OM breakdown } \\
(\%)\end{array}$ \\
\hline I 1) & 186 & 72 \\
\hline $\mathbf{M}^{3)}$ & $260 \pm 1$ & $26 \pm 2$ \\
\hline $\mathrm{MPo}{ }^{3)}$ & $238 \pm 14$ & $29 \pm 3$ \\
\hline $\mathrm{MPe}{ }^{2)}$ & $249 \pm 10$ & $30 \pm 3$ \\
\hline M Gl 3 ) & $232 \pm 13$ & $32 \pm 4$ \\
\hline $\mathbf{S}^{1)}$ & 213 & 30 \\
\hline S Po ${ }^{1)}$ & 227 & 14 \\
\hline $\mathrm{SPe}{ }^{1)}$ & 201 & 24 \\
\hline S GI ${ }^{1)}$ & 169 & 31 \\
\hline
\end{tabular}

Shives treated with $P$. ostreatus showed a relatively low OM breakdown (which was in line with the low biogas production). Other differences were small. There seemed to be no clear relations between a small non-digestible fraction and a high OM breakdown. 


\section{Discussion and conclusion}

From the first experiment it was clear that many combinations of substrates and fungi resulted in growth/colonization, except for combinations with Greendal digestate. Most likely, this is due to compounds with fungicidal properties in the biodigester feeds and not on the nutrient composition of the substrates, since on ACRRES digestate fungal growth occurred for several fungi species. The most successful combinations were those with $P$. eryngii, $P$. ostreatus and G. lucidum on ACRRES digestate, flax shives and cow manure, based on visual signs of fungal colonisation (air mycelium).

Several similar results have been previously described by other authors: Siwulski et al (2010) concluded that $P$. ostreatus could very well grow on flax shives, or digestate (Zhou et al, 2018). Jasinska et al (2017) found that G. lucidum could very well grow on anaerobically digested food waste. Several agricultural residues (either from processing or from anaerobic digestion) thus show potential for growing mushrooms. Common mushrooms (Agaricus spp.) were also successfully cultivated on several digestates (partly or fully) by Stoknes et al (2013) and Jasinka et al (2016). O'Brien et al (2019) found that solid digestates of food waste and cow manure could be used to replace non-local substrates in the cultivation of $P$. ostreatus with similar yields.

There is no general correlation between colonization of the substrates with mycelium and either degradation of components such as lignin or growth of fruiting bodies for mushroom production. As such, nothing can be concluded on these topics.

Table 8 shows biogas productions from several other substrates.

Table 8 Measured biogas and methane productions (in $\mathrm{nm}^{3}$ ) on total product basis and biogas qualities compared to calculated values based on single substrates.

\begin{tabular}{|c|c|c|c|c|c|}
\hline Substrate & DM $\%$ & $\begin{array}{l}\text { Biogas quality } \\
\left(\% \mathrm{CH}_{4}\right)\end{array}$ & $\begin{array}{l}\text { Biogas } \\
\text { per ton } \\
\text { product }\end{array}$ & $\begin{array}{l}\text { Biogas } \\
\text { per ton } \\
\text { DM }\end{array}$ & Reference \\
\hline Sewage sludge & 5 & 65 & 15 & 300 & SGC (2012) \\
\hline Fish waste & 42 & 71 & 537 & 1279 & SGC (2012) \\
\hline Straw & 78 & 70 & 207 & 265 & SGC (2012) \\
\hline Food waste & 33 & 63 & 204 & 618 & SGC (2012) \\
\hline Cattle slurry & 9 & 65 & 22 & 244 & SGC (2012) \\
\hline Potato haulm & 15 & 56 & 68 & 453 & SGC (2012) \\
\hline Slaughter waste & 16 & 63 & 92 & 575 & SGC (2012) \\
\hline Pig slurry & 8 & 65 & 26 & 325 & SGC (2012) \\
\hline Cow manure & & & 56 & & Biogas-E (2017) \\
\hline Pig manure & & & 55 & & Biogas-E (2017) \\
\hline Poultry manure & & & 48 & & Biogas-E (2017) \\
\hline Aerobic sludge & & & 13 & & Biogas-E (2017) \\
\hline Grass silage & & & 172 & & Biogas-E (2017) \\
\hline Cow manure & 8 & & 20 & 250 & Dijk, van and Durksz (2014) \\
\hline Corn silage & 33 & & 200 & 600 & Dijk, van and Durksz (2014) \\
\hline Black soldier fly frass & 63 & 58 & 285 & 454 & Elissen et al (2019) \\
\hline Vermicompost & 32 & 38 & 10 & 32 & Elissen et al (2019) \\
\hline Champost & 37 & 48 & 51 & 139 & Elissen et al (2019) \\
\hline Digestate & 9 & 60 & 11 & 117 & Elissen et al (2019) \\
\hline Black soldier fly frass & 53 & 58 & 274 & 521 & This report \\
\hline Cow manure & 33 & 54 & 61 & 184 & This report \\
\hline Cow manure $P$. ostreatus & 31 & 52 & 58 & 186 & This report \\
\hline Cow manure $P$. eryngii & 33 & 54 & 69 & 208 & This report \\
\hline Cow manure G. Iucidum & 32 & 53 & 72 & 226 & This report \\
\hline Flax shives & 29 & 59 & 73 & 255 & This report \\
\hline Flax shives $P$. ostreatus & 26 & 59 & 35 & 137 & This report \\
\hline Flax shives $P$. eryngii & 25 & 56 & 43 & 170 & This report \\
\hline Flax shives G. Iucidum & 23 & 56 & 48 & 209 & This report \\
\hline
\end{tabular}

In general, (average) biogas productions from the different substrates with or without fungal pretreatment did not differ to a large extent and were relatively low $\left(35-73 \mathrm{~nm}^{3}\right.$ biogas per ton product) except for that from insect frass ( $274 \mathrm{~nm}^{3}$ biogas per ton product): It was high and similar to that found in a previous experiment (Elissen et al, 2019). When comparing the numbers to other data, 
biogas production from untreated flax shives was similar to that of straw and that of cow manure was somewhat lower than numbers found by other authors. All three species used for pre-treatment are WRF (basidiomycetes). P. ostreatus, $P$ eryngii and G. Iucidum are all able to break down lignin to a certain extent and could potentially make the cow manure more biodegradable for biogas production. According to Tuyen et al (2012) P. ostreatus does not preferentially break down lignin while $P$. eryngii does. An increased biogas production and the efficiency of fungal treatment are linked to the lignin content of the substrate and at low lignin concentrations fungal treatment does not seem useful (Tuyen et al 2013). For the samples of solid fraction of cow manure the lignin content is not known. Pečar et al (2020) did not find any increase in biogas production after treatment of chicken manure/sawdust/straw with $P$. ostreatus. This resembles our results in which treatment with $P$. ostreatus did not increase the amount of biogas that could be collected. Treatment of cow manure with the other two fungi $P$. eryngii and $G$. lucidum also did not lead to significantly higher biogas productions in our experiments, which contradicts results by Tuyen et al (2012). Their results suggest that G. Iucidum is also able to selectively degrade lignin, which leaves cellulose to methanogens. In our tests lignin content was not analysed. It could however well be that shives have a low lignin content compared to cow manure, so fungi would start with (hemi)cellulose degradation instead, which leads to a lower biogas production.

In conclusion, from our results it can be concluded that the solid fractions of certain digestates and cow manure and flax shives can be colonized by several fungi, of which $P$. ostreatus, $P$. ergyngii and G. Iucidum were most successful. One of the used digestates did not result in any fungal growth. For practical applications, the amount of mushroom biomass produced and lignin degraded on each substrate should be tested and which pretreatment of the substrates is necessary for removal of pathogens from the manure/digestate fractions. Fungal pre-treatment of the solid fraction of cow manure did not lead to significantly increased biogas production when using $P$. ostreatus, $P$. eryngii and $G$. lucidum. The same was true for flax shives when using $P$. eryngii and $G$. lucidum, but pretreatment with $P$. ostreatus led to lower biogas productions. 


\section{Recommendations}

For successful combinations of fungi and substrates from the first experiment further experiments could be performed with emphasis on the following aspects:

- Which pretreatment of the substrates is necessary for removal of pathogens when using manure/digestate fractions?

- Detailed analysis of the growth substrates, a.o. recalcitrant components before and after incubation

- Quantify mycelium growth and (if possible) relate to breakdown of recalcitrant components in the substrates

- $\quad$ Allow fruiting bodies to develop to estimate biomass yield for commercial mushroom production on alternative substrates

- Evaluate the (economic) potential of the waste streams as a steady year-round bulk substrate

In our second experiment we could not significantly prove that fungal pre-treatment of manure and shives led to increased biogas production from these substrates, even though some positive effects seemed to take place. For future experiments the following aspects should be taken into account:

- It would be advisable to study the underlying enzymatic mechanisms, i.e. determine enzyme concentrations in the substrates. Quantification of biomass growth, and breakdown of cellulose, lignin and hemicellulose are interesting parameters for future experiments.

- $\quad$ Sterilization of the substrates, as was done in this test, may prevent growth of e.g. competitor fungi and/or (non-methanogenic) bacteria on the nutrients released by fungal treatment, but is costly for large-scale operations. It would be interesting to compare biogas productions for sterilized and non-sterilized substrates. According to Rouches et al (2016) it would be advisable to avoid loss of fermentable sugars. In addition he suggests careful selection of WRF strains to optimize selective delignification and optimization of pretreatment conditions (water content, aeration, temperature, nutrient supplementation and pretreatment duration). 


\section{References}

1. Ali, S.S. and J. Sun, 2015. Physico-chemical pretreatment and fungal biotreatment for park wastes and cattle dung for biogas production. SpringerPlus 4: 712

2. Baars, J. 2020. Personal communication June 10th, 2020 (CNC Grondstoffen)

3. De Groene Rekenkamer, 2015. Website https://groene-rekenkamer.nl/4506/debiomassavergister/ (in Dutch)

4. Elissen, H., S. Hol and R. van der Weide, 2019. Methane production from insect, worm and mushroom waste streams and combinations. Report WPR-817. Wageningen: Stichting Wageningen Research, Wageningen Plant Research, Business Unit Field Crops

5. Florian, M., B. Abdellatif, T. Eric, D. Claire, S. JeanPhilippe, and C. Hélène, 2013. Lignocellulosic materials into biohydrogen and biomethane: impact of structural features and pretreatment. Crit. Rev. Env. Sci. Technol. 43: 260-322

6. Hagos, K., J. Zong, D. Li, C. Liu and X. H. Lu, 2016. Anaerobic co-digestion process for biogas production: progress, challenges and perspectives. Renew. Sust. Energ. Rev. 76: 1485-1496

7. Jasińska, A.J., E. Wojciechowska, W. Krzesiński, T. Spiżewski, K. Stoknes and K. Krajewska, 2016. Mushroom cultivation on substrates with addition of anaerobically digested food waste. Acta Hortic. 1123: 199-206

8. Jasińska, A., L. Dawidowicz, M. Siwulski and P. Kilinowski, 2017. Growth of mycelium of different edible and medicinal mushrooms on medium supplemented with digestate from $A D$ biogas plant. Notulae Botanicae Horti Agrobotanici Cluj-Napoca, 45(2): 498-506

9. Jurak, E. 2015. How Mushrooms feed on compost: Conversion of carbohydrates and lignin in industrial wheat straw based compost enabling the growth of Agaricus bisporus. PhD thesis, Wageningen University, Wageningen, the Netherlands, $156 \mathrm{pp}$.

10. Monlau, F., C. Sambusiti, A. Barakat, X. M. Guo, E. Latrille, E. Trably, J. P. Steyer and H. Carrere, 2012. Predictive models of biohydrogen and biomethane production based on the compositional and structural features of lignocellulosic materials. Environ. Sci. Technol. 46 (21): 12217-12225

11. O'Brien, B. J., E. Milligan, J. Carver and E.D. Roy, 2019. Integrating anaerobic co-digestion of dairy manure and food waste with cultivation of edible mushrooms for nutrient recovery Bioresour. Technol., 285: Article 121312

12. Qiao, W., X. Yan, J. Ye, Y. Sun, W. Wang and Z. Zhang, 2011. Evaluation of biogas productionfrom different biomass wastes with/without hydrothermal pretreatment. Renew. Energy 36 (12): 3313-3318

13. Rouches, E., I. Herpoël-Gimbert, J.P. Steyer and H. Carrere, 2016. Improvement of anaerobic degradation by white-rot fungi pretreatment of lignocellulosic biomass: A review. Renewable and Sustainable Energy Reviews 59: 179-198

14. Stoknes, K., D. M. Beyer and E. Norgaard, 2013. Anaerobically digested food waste in compost for Agaricus bisporus and Agaricus subrufescens and its effect on mushroom productivity. J. Sci. Food Agric. 93 (9): 2188-2200

15. Tuyen. D. V., H. N. Phuong, J. W. Cone, J. J. P. Baars, A. S. M. Sonnenberg and W. H. Hendriks, 2013. Effect of fungal treatments of fibrous agricultural by-products on chemical composition and in vitro rumen fermentation and methane production. Bioresource Technology 129: 256-263

16. Tuyen, V. D., J. W. Cone, J. J. P. Baars, A. S. M. Sonnenberg and W. H. Hendriks, 2012. Fungal strain and incubation period affect chemical composition and nutrient availability of wheat straw for rumen fermentation. Bioresource Technology 111:336-342

17. Wróbel-Kwiatkowska, M., S. Jabłoński, J. Szperlik, L. Dymińska, M. Łukaszewicz, W. Rymowicz, J. Hanuza and J. Jan Szopa, 2015. Impact of CAD-deficiency in flax on biogas production. Transgenic Res 24: 971-978

18. Xu, N., S. Liu, F. Xin, J. Zhou, H. Jia, J. Xu, M. Jiang and W. Dong, 2019. Biomethane production from lignocellulose: Biomass recalcitrance and its impacts on anaerobic digestion. Front. Bioeng. Biotechnol. 7:191 
19. Yildirim, E., O. Ince, S. Aydın and B. K. Ince, 2017. Improvement of biogas potential of anaerobic digesters using rumen fungi. Renewable Energy 109: 346-353 


\section{Annex 1 Growth results of 10 different fungal species on four substrates after 4 weeks}

\begin{tabular}{lllll}
\hline Fungus & ACRRES digestate & Greendal digestate & Cow manure & Shives \\
Agaricus subrufescens & No growth & No growth & Partly colonized & Fully colonized \\
\hline Agrocybe aegerita & Fully colonized & No growth & Fully colonized & Fully colonized \\
\hline Bjerkandera adusta & No growth & No growth & Hardly colonized & Hardly colonized \\
\hline Ceriporiopsis subvermispora & No growth & No growth & No growth & No growth \\
\hline Coprinopsis atramentaria & No growth & No growth & Fully colonized & Partly colonized \\
\hline Coprinus comatus & No growth & No growth & Fully colonized & Fully colonized \\
\hline Ganoderma lucidum & No growth & No growth & Fully colonized & Partly colonized \\
\hline Lentinula edodes & No growth & No growth & Partly colonized & Partly colonized \\
\hline Pleurotus eryngii & Fully colonized & No growth & Fully colonized & Fully colonized \\
\hline Pleurotus ostreatus & Fully colonized & No growth & Fully colonized & Fully colonized \\
\hline Non-inoculated control & Clean & Clean & Clean & Clean \\
\hline
\end{tabular}

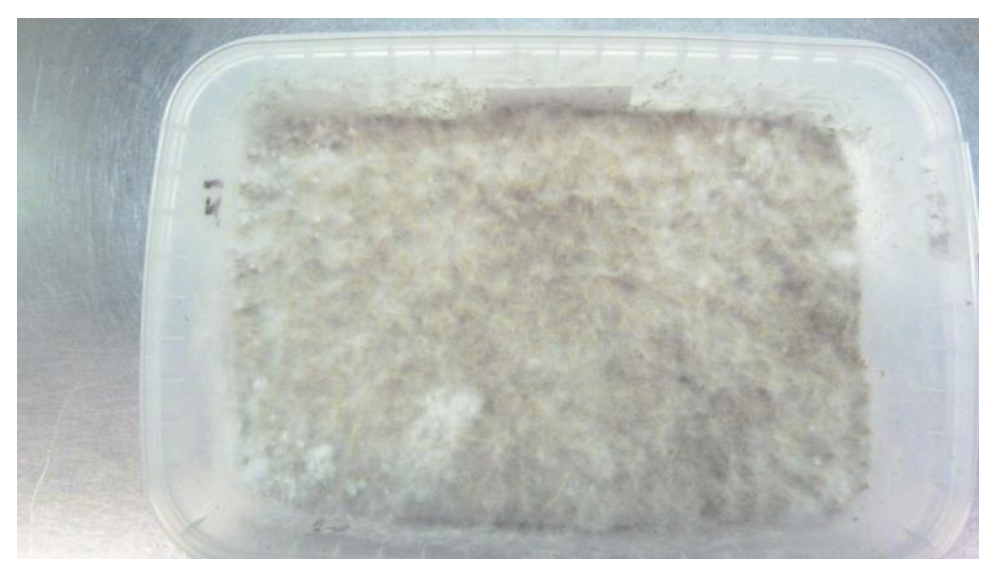

Example of fully colonized cow manure

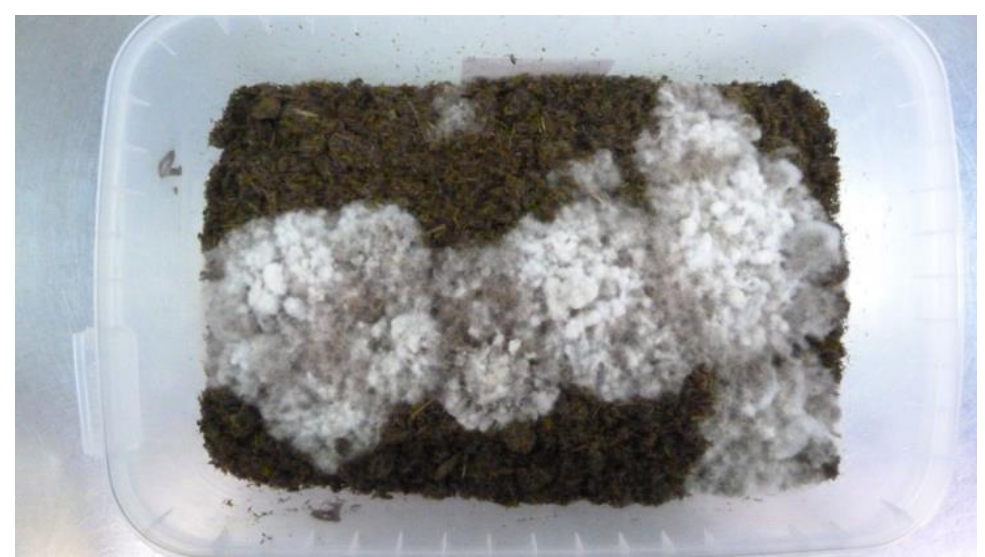

Example of partly colonized cow manure 

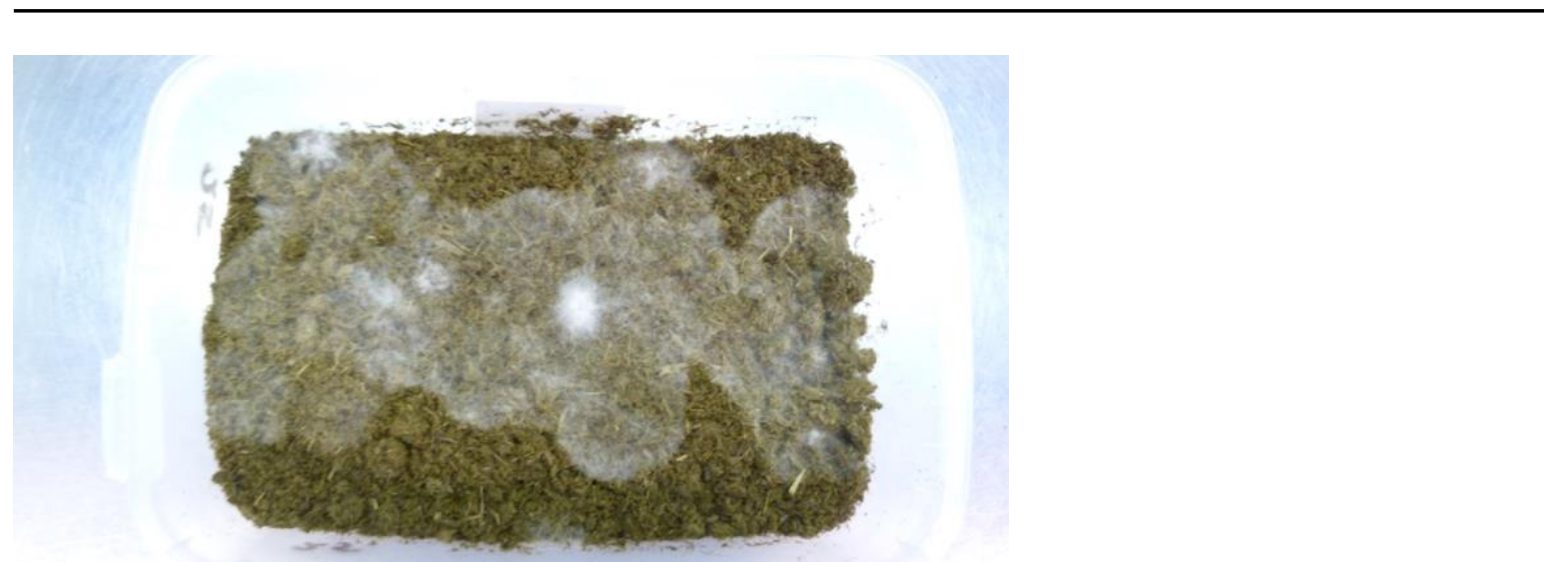

Example of hardly colonized cow manure 


\section{Annex $2 \mathrm{pH}$ values and substrate dosages at start and end of anaerobic digestion tests $(n=3)$}

$\mathrm{Po}=$ Pleurotus ostreatus, $\mathrm{Pe}=$ Pleurotus eryngii, $\mathrm{Gl}=$ Ganoderma lucidum, $\mathrm{D}=$ digestate, $\mathrm{I}=$ insect frass, $M=$ manure, $S$ = shives. Numbers behind substrate names represent boxes, other numbers represent triplicates from each box.

\begin{tabular}{lcccccc} 
& pH start & \multicolumn{1}{c}{$\mathrm{pH}$ end } \\
\hline Test substrates & $\mathbf{1}$ & $\mathbf{2}$ & $\mathbf{3}$ & $\mathbf{1}$ & $\mathbf{2}$ & $\mathbf{3}$ \\
\hline Insect frass & 7.77 & 7.77 & 7.77 & 7.42 & 7.42 & 7.43 \\
\hline Manure control 2 & 7.79 & 7.79 & 7.79 & 7.74 & 7.74 & 7.74 \\
\hline Manure control 2 repeat & 7.80 & 7.79 & 7.80 & 7.73 & 7.76 & 7.76 \\
\hline Manure control 3 repeat & 7.81 & 7.81 & 7.81 & 7.7 & 7.7 & 7.7 \\
\hline Manure Po 1 & 7.79 & 7.80 & 7.80 & 7.71 & 7.71 & 7.71 \\
\hline Manure Po 2 & 7.78 & 7.78 & 7.78 & 7.56 & 7.56 & 7.57 \\
\hline Manure Po 3 & 7.80 & 7.81 & 7.80 & 7.59 & 7.61 & 7.59 \\
\hline Manure Pe 1 & 7.80 & 7.81 & 7.81 & 7.56 & 7.55 & 7.55 \\
\hline Manure Pe 2 & 7.80 & 7.80 & 7.79 & 7.57 & 7.58 & 7.58 \\
\hline Manure Gl 1 & 7.81 & 7.80 & 7.80 & 7.56 & & 7.56 \\
\hline Manure GI 2 & 7.79 & 7.81 & 7.80 & 7.51 & 7.51 & 7.51 \\
\hline Manure GI 3 & 7.85 & 7.85 & 7.86 & 7.63 & 7.59 & 7.59 \\
\hline Shives control & 7.86 & & 7.86 & 7.61 & & 7.60 \\
\hline Shives Po & 7.87 & 7.86 & 7.86 & 7.70 & 7.68 & 7.68 \\
\hline Shives Pe & 7.82 & 7.82 & 7.83 & 7.67 & 7.66 & 7.64 \\
\hline Shives Gl & 7.82 & 7.81 & 7.83 & 7.61 & 7.6 & 7.6 \\
\hline
\end{tabular}

\begin{tabular}{|c|c|c|c|c|}
\hline & & 1 & 2 & 3 \\
\hline Test substrates & & $\mathbf{g}$ & $\mathbf{g}$ & $\mathbf{g}$ \\
\hline \multirow[t]{2}{*}{ Insect frass } & D & 200.3 & 199.2 & 199.8 \\
\hline & $\mathbf{I}$ & 1.3 & 1.3 & 1.3 \\
\hline \multirow[t]{2}{*}{ Manure control 2} & D & 200.1 & 199.7 & 199.8 \\
\hline & $\mathbf{M}$ & 2.2 & 2.2 & 2.2 \\
\hline \multirow[t]{2}{*}{ Manure control 2 repeat } & D & 200.0 & 200.7 & 199.7 \\
\hline & $\mathbf{M}$ & 2.17 & 2.2 & 2.2 \\
\hline \multirow[t]{2}{*}{ Manure control 3 repeat } & D & 200.1 & 200.0 & 200 \\
\hline & $\mathbf{M}$ & 2.07 & 2.08 & 2.08 \\
\hline \multirow[t]{2}{*}{ Manure Po 1} & D & 200.5 & 200.2 & 200.1 \\
\hline & $\mathbf{M}$ & 2.4 & 2.4 & 2.4 \\
\hline \multirow[t]{2}{*}{ Manure Po 2} & D & 200.2 & 200.4 & 200.4 \\
\hline & $\mathbf{M}$ & 2.3 & 2.3 & 2.3 \\
\hline \multirow[t]{2}{*}{ Manure Po 3} & D & 199.6 & 199.9 & 199.9 \\
\hline & $\mathbf{M}$ & 2.2 & 2.2 & 2.2 \\
\hline \multirow[t]{2}{*}{ Manure Pe 1} & D & 200.3 & 200.1 & 200.5 \\
\hline & $\mathbf{M}$ & 2.1 & 2.1 & 2.1 \\
\hline \multirow{2}{*}{ Manure Pe 2} & D & 199.8 & 200.0 & 199.9 \\
\hline & $\mathbf{M}$ & 2.1 & 2.1 & 2.1 \\
\hline \multirow[t]{2}{*}{ Manure GI 1} & D & 199.5 & 200.1 & 200.1 \\
\hline & M & 2.2 & 2.2 & 2.2 \\
\hline \multirow[t]{2}{*}{ Manure GI 2} & D & 200.0 & 200.3 & 200.0 \\
\hline & $\mathbf{M}$ & 2.3 & 2.3 & 2.3 \\
\hline \multirow[t]{2}{*}{ Manure GI 3} & D & 199.8 & 199.8 & 200.8 \\
\hline & M & 2.3 & 2.3 & 2.3 \\
\hline \multirow[t]{2}{*}{ Shives control } & D & 200.9 & 200.1 & 200.0 \\
\hline & $\mathbf{S}$ & 2.4 & 2.4 & 2.4 \\
\hline \multirow[t]{2}{*}{ Shives Po } & D & 200.9 & 199.8 & 199.9 \\
\hline & $\mathbf{S}$ & 2.7 & 2.7 & 2.7 \\
\hline \multirow[t]{2}{*}{ Shives Pe } & D & 200.3 & 200.0 & 200.1 \\
\hline & $\mathbf{S}$ & 2.7 & 2.7 & 2.7 \\
\hline \multirow[t]{2}{*}{ Shives GI } & D & 200.7 & 200.3 & 200.2 \\
\hline & $\mathbf{S}$ & 3.1 & 3.1 & 3.1 \\
\hline
\end{tabular}




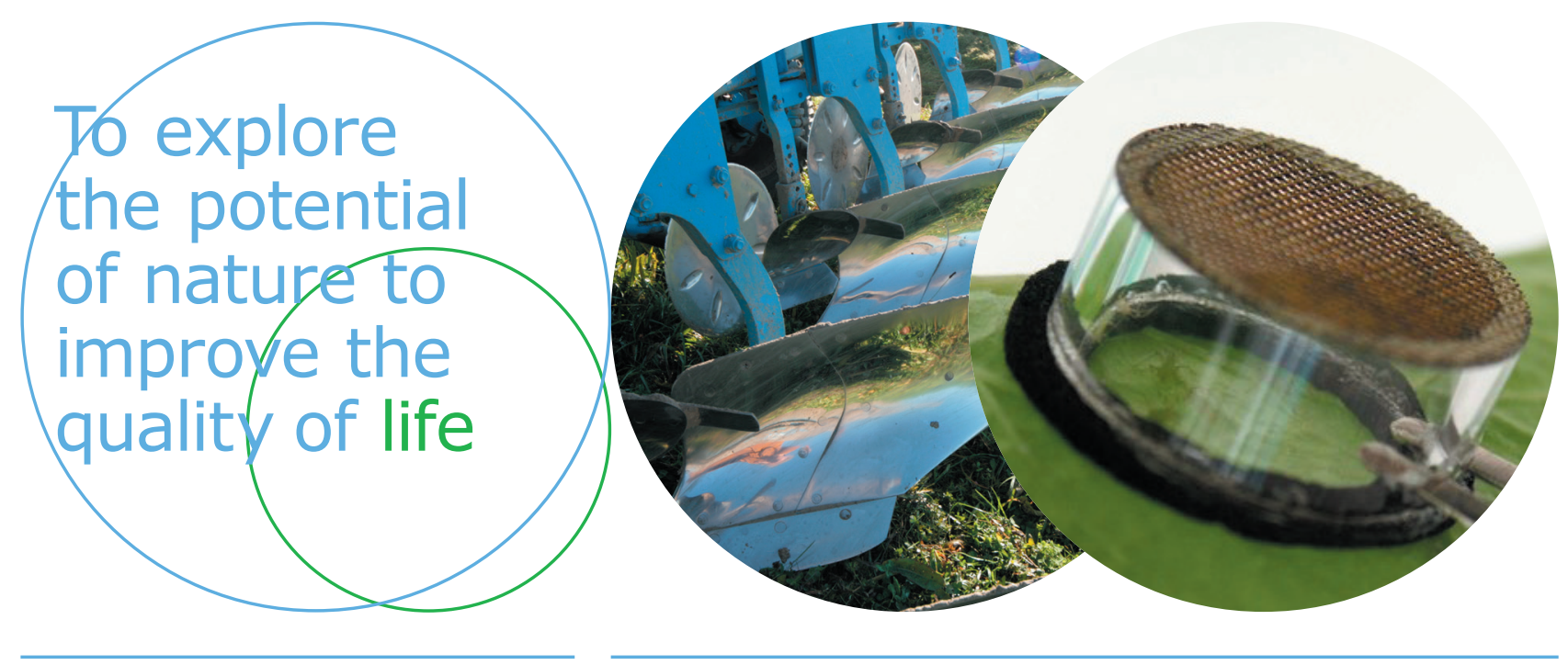

Wageningen University \& Research

\section{Field Crops}

Edelhertweg 1

Postbus 430

8200 AK Lelystad

T (+31)3202911 11

www.wur.nl/openteelten

www.wur.eu/fieldcrops

Rapport WPR-832
The mission of Wageningen University \& Research is "To explore the potential of nature to improve the quality of life". Under the banner Wageningen University \& Research, Wageningen University and the specialised research institutes of the Wageningen Research Foundation have joined forces in contributing to finding solutions to important questions in the domain of healthy food and living environment. With its roughly 30 branches, 6,500 employees $(5,500 \mathrm{fte})$ and 12,500 students, Wageningen University \& Research is one of the leading organisations in its domain. The unique Wageningen approach lies in its integrated approach to issues and the collaboration between different disciplines. 